\title{
Fine-tuning the ubiquitin code at DNA double-strand breaks: deubiquitinating enzymes at work
}

\author{
Elisabetta Citterio* \\ Division of Molecular Genetics, Netherlands Cancer Institute, Amsterdam, Netherlands
}

Ubiquitination is a reversible protein modification broadly implicated in cellular functions. Signaling processes mediated by ubiquitin (ub) are crucial for the cellular response to DNA double-strand breaks (DSBs), one of the most dangerous types of DNA lesions. In particular, the DSB response critically relies on active ubiquitination by the RNF8 and RNF168 ub ligases at the chromatin, which is essential for proper DSB signaling and repair. How this pathway is fine-tuned and what the functional consequences are of its deregulation for genome integrity and tissue homeostasis are subject of intense investigation. One important regulatory mechanism is by reversal of substrate ubiquitination through the activity of specific deubiquitinating enzymes (DUBs), as supported by the implication of a growing number of DUBs in DNA damage response processes. Here, we discuss the current knowledge of how ub-mediated signaling at DSBs is controlled by DUBs, with main focus on DUBs targeting histone $\mathrm{H} 2 \mathrm{~A}$ and on their recent implication in stem cell biology and cancer.

Keywords: ubiquitin, DNA double-strand breaks (DSBs), deubiquitinating enzymes (DUBs), histone H2A, chromatin, DNA damage response (DDR), hematopoietic stem cell (HSC), cancer

\section{Introduction} Elisabetta Citterio, Division of Molecular Genetics, Netherlands Cancer Institute, Plesmanlaan 121,

1066 CX Amsterdam, Netherlands e.citterio@nki.nl

Specialty section:

This article was submitted to Cancer Genetics,

a section of the journal

Frontiers in Genetics

Received: 29 June 2015

Accepted: 23 August 2015

Published: 08 September 2015

Citation:

Citterio E (2015) Fine-tuning the ubiquitin code at DNA double-strand breaks: deubiquitinating enzymes at work.

Front. Genet. 6:282.

doi: 10.3389/fgene.2015.00282

The ability of cells to maintain the integrity of their genome is crucial for organism physiology, including stem cell and tissue homeostasis and cancer avoidance (Jackson and Bartek, 2009; Blanpain et al., 2011; Behrens et al., 2014). A complex surveillance network protects cells from the continuous threat of exogenous as well as endogenously generated genotoxic insults. This includes multiple pathways, collectively called the DNA damage response (DDR), which ensure effective DNA damage detection, signaling, and repair (Ciccia and Elledge, 2010). DDR coordinates DNA repair with vital cellular functions, including transcription and DNA replication, and determines the fate of the cell after DNA damage. Post-translational modification of proteins by the 76 amino acid protein ubiquitin (ub) plays a central role in various aspects of DDR (Lukas et al., 2011; Jackson and Durocher, 2013). ub is conjugated to lysine residues (Lys, K) in target proteins through the activities of E1, E2, and E3 enzymes (Komander and Rape, 2012). Proteins can be modified with one ub moiety (monoubiquitination) or with polymeric ub chains. The use of one of the seven lysines of ub (K6, K11, K27, K29, K33, K48, and K63) or the N-terminal amine ("linear") for chain formation

Abbreviations: BM, bone marrow; FA, Fanconi anemia; HR, homologous recombination; HSC, hematopoietic stem cell; HSPC, hematopoietic stem and progenitor cell; IRIFs, ionizing radiation induced foci; K63-ub, lysine 63-linked ubiquitin chains; PAR, poly(ADP-ribose); PARP, poly(ADP-ribose) polymerase; PcG, polycomb group protein; ub, ubiquitin; uH2A, mono-ubiquitinated histone $\mathrm{H} 2 \mathrm{~A}$; uH2B, mono-ubiquitinated histone $\mathrm{H} 2 \mathrm{~B}$. 
allows diverse conformations, conferring a great signaling potential to the ub system. The resulting ub "code" can target the substrate for degradation, or regulate its interactions, localization or activity. Typically, K48-linked ub chains serve as proteasomal degradation signals, while K63-linked chains (K63-ub) are nondegradative. The ub code is ultimately "read" by proteins endowed with ub binding domains, which determine distinct outcomes in the cell (Komander and Rape, 2012).

Modification by ub is regulated by the catalytic activities of deubiquitinating enzymes (DUBs; also known as deubiquitinases or deubiquitylating enzymes), which can cleave ub from proteins or process all types of ub-chains (Komander et al., 2009). The human genome encodes for $\approx 90$ potential DUBs, many of which are strongly implicated in cancer and other pathologies, including neurodegenerative, hematological and infectious diseases (Nijman et al., 2005; Komander et al., 2009). DUBs can be subdivided in five subfamilies, four belonging to the cysteine proteases group [ubiquitin-specific proteases (USPs), ovarian tumor proteases (OTUs), ubiquitin C-terminal hydrolases (UCHs) and Josephin domain DUBs], and one consisting of the JAMM/MPN+ family of metalloproteases (Komander et al., 2009). One key function of DUBs is the generation of free ub from ub precursors. Second, by cleaving mono-ub adducts or poly-ub chains from target proteins, DUBs can reverse a non-degradative $u b$ signal or stabilize target proteins by rescuing them from proteasomal or lysosomal degradation. Third, DUBs can cleave the isopeptide bond from within the ub polymer, an activity that allows editing ub chains and thereby ub-mediated signal (Komander and Rape, 2012; Heride et al., 2014). Beside the catalytic domain, DUBs contain multiple domains, some of which aid in substrate or in proteinprotein interactions, endowing the DUBs with the ability to display specificity at the protein substrate level as well as at the level of ub chain types (Komander and Rape, 2012).

It has become clear that reversal of substrate ubiquitination by DUBs is a critical regulatory mechanism throughout the DDR. In this review, I will focus on recent discoveries involving DUBs in the modulation of ub-mediated DDR at DNA doublestrand breaks (DSBs), with emphasis on histone H2A targeting DUBs. Readers are referred to recent reviews for a more comprehensive overview of DUB functions (Komander et al., 2009; Clague et al., 2012; Belle and Nijnik, 2014; Sahtoe and Sixma, 2015), ub and DUBs roles in DDR (Ulrich, 2012; Jackson and Durocher, 2013; Jacq et al., 2013; Brown and Jackson, 2015) or for detailed information regarding the ubiquitination/deubiquitination process (Komander and Rape, 2012; Heride et al., 2014).

\section{Ubiquitin-Mediated DDR Signaling at DNA Double-Strand Breaks}

In eukaryotic cells, the packaging of DNA with histone proteins into chromatin, the basic unit being the nucleosome, has major impact on DNA damage signaling and repair. This is because on one hand the compact organization of chromatin intrinsically limits the degree of access to DNA. At the same time, however, chromatin provides a sensitive regulatory platform for DDR through post-translational modifications to both chromatin components (i.e., histones) and non-chromatin proteins (Lukas et al., 2011). Non-proteolytic (mono-) ubiquitination of histones is a prevalent modification in mammalian cells (Goldknopf and Busch, 1977). Work from several groups has shown that histone ubiquitination at the chromatin surrounding DSBs is a key step in DDR activation (Lukas et al., 2011; Figure 1). Phosphorylation of the histone variant $\mathrm{H} 2 \mathrm{AX}$ (yielding $\gamma \mathrm{H} 2 \mathrm{AX}$ ) by the ataxia telangectasia mutated (ATM) checkpoint kinase promotes the binding of the E3 ligase RNF8 through the mediator protein MDC1 to damage sites, where it initiates ub signaling (Huen et al., 2007; Kolas et al., 2007; Mailand et al., 2007; Wang and Elledge, 2007). A second E3, RNF168, is then recruited through RNF8ubiquitinated substrates to the proximity of the lesion and starts catalysis of $\mathrm{H} 2 \mathrm{~A} / \mathrm{H} 2 \mathrm{AX}$ ubiquitination on Lys 13 (H2AK13ub) and/or Lys15 (H2AK15ub; Gatti et al., 2012; Mattiroli et al., 2012). The coordinated activities of RNF8/RNF168 with HERC2 and the E2 Ubc13 lead to the formation on H2A/H2AX of K63ub, a prevalent ub linkage at DSBs (Doil et al., 2009; Pinato et al., 2009; Stewart et al., 2009; Gatti et al., 2012; Mattiroli et al., 2012). A major outcome of RNF8/RNF168-mediated ubiquitination is recruitment/stable accumulation of DDR proteins at the lesion, with the tumor suppressors BRCA1 (breast cancer 1, early onset) and 53BP1 (p53 binding protein 1) representing the two key effectors of the pathway (Lukas et al., 2011). Importantly, the interplay between BRCA1 and 53BP1 determines effective DSB repair by one of the two major DSB repair pathways, with BRCA1 promoting the error-free homologous recombination (HR) process while 53BP1 committing to non-homologous end joining (NHEJ; Cao et al., 2009; Bouwman et al., 2010; Bunting et al., 2010). By influencing the relative kinetics of these DDR effectors at DSBs, the RNF8 pathway is functionally implicated in determining the repair pathway choice, which is critical to genome maintenance (Panier and Boulton, 2014).

53BP1 recognizes the DSB-specific H2AK13/15ub mark through its UDR (ubiquitination-dependent recruitment) motif, which, together with the Tudor domain reads a bivalent ubiquitination-methylation signal at damage sites (FradetTurcotte et al., 2013). While no ub-binding domains have been yet identified in BRCA1, it is clear that BRCA1 stable accumulation at the DSB-flanking chromatin is dependent on its interaction with RAP80, a protein that binds K63-linked ub conjugates through its tandem ub-interacting motifs (Huen et al., 2007; Kolas et al., 2007; Mailand et al., 2007; Wang et al., 2007). Initial BRCA1 recruitment, however, appears independent of Rap80 (Hu et al., 2011; Yin et al., 2012) and involves binding of a small fraction of BRCA1 directly at the DNA break through interaction with the DSB recognition factor Nbs1 (Goldstein and Kastan, 2015).

Signaling through chromatin ub during DDR is multifaceted, engaging several E3 ligases and modification by ub and ub-like proteins of (non-)histone proteins (Lukas et al., 2011; Jackson and Durocher, 2013; Brown and Jackson, 2015). One of these E3 is the PcG transcriptional repressor complex RING1b/BMI1 (Chou et al., 2010; Ismail et al., 2010; Gieni et al., 2011; Ginjala et al., 2011; Vissers et al., 2012). RING1b/BMI1 is part of the polycomb 


\section{A}

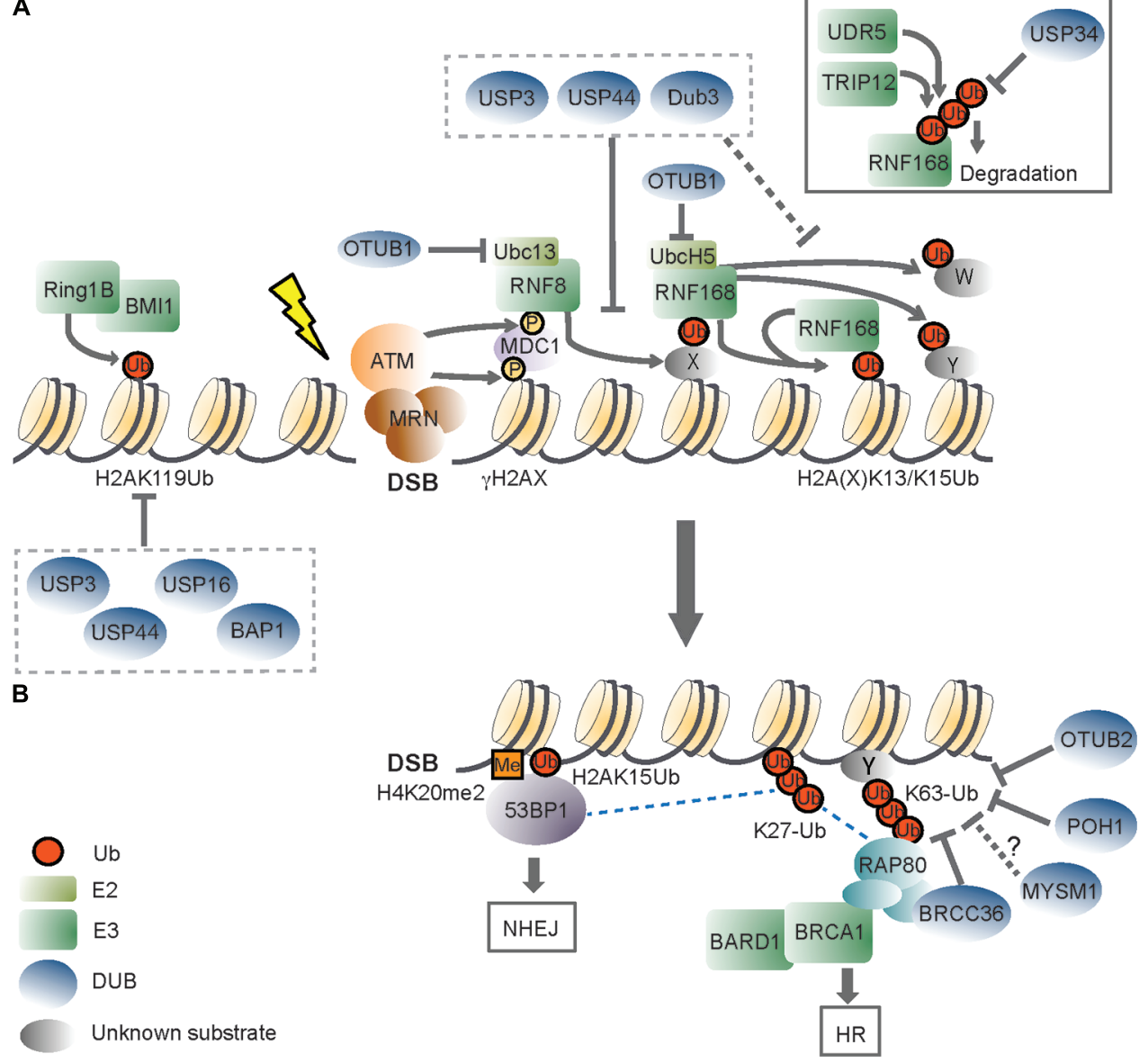

FIGURE 1 | The role of deubiquitinating enzymes in the chromatin-based response to DNA double-strand breaks. (A) Recognition of a DNA double-strand break (DSB) by the MRN (MRE11-RAD50-NBS1) complex initiates DDR signaling, triggering ATM (ataxia-telangectasia mutated) kinase-dependent phosphorylation of $\mathrm{H} 2 \mathrm{AX}(\gamma \mathrm{H} 2 \mathrm{AX})$. ATM phosphorylates also MDC1 (mediator of DNA damage checkpoint protein 1), which is recognized by the RING finger 8 (RNF8) E3 ligase. The activity of RNF8 is required for recruitment of a second E3, RNF168. RNF168 mono-ubiquitinates H2A-type histones on Lys13 and Lys15 (H2A(X)K13/K15Ub), and the concerted action of RNF8/RNF168 leads to the formation of K63-linked ubiquitin (Ub) chains on these lysines and to ubiquitination of other substrates $(\mathrm{Y}$ and $\mathrm{W})$. RNF168 can bind to its own products, thereby amplifying chromatin ubiquitination around the DSB. OTUB1 opposes RNF168 activity in a non-catalytic manner, by binding to the E2 ubiquitin-conjugating enzymes UBC13 and UbcH5. USP3, USP44, and Dub3 DUB activities impair RNF168 recruitment, suggesting that they can target RNF8 substrate(s). These DUBs may also cleave RNF168-mediated ubiquitinated $\mathrm{H} 2 \mathrm{~A}(\mathrm{X})$. Excessive RNF168-dependent chromatin ubiquitination is limited by the TRIP12 and UBR5 E3 ligases, which target RNF168 for proteasomal degradation. USP34, instead, counteracts DSB-induced RNF168 ubiquitination. DSBs also trigger the recruitment of the Polycomb group E3 RING1B/BMl1, which mono-ubiquitinates H2A on Lys119 (H2AK119Ub) to locally repress transcription. USP16 and BAP1 target the H2AK119Ub mark, and USP16 activity is required for re-activation of DSB-induced transcriptional silencing. USP3 and USP44 oppose to steady-state mono-ubiquitinated H2A, which is primarily constituted by H2AK119Ub. (B) DSB-induced ubiquitin signals are recognized by downstream DDR factors. 53BP1 (p53 binding protein 1) recognizes the H2AK15Ub mark by its UDR (ubiquitination-dependent recruitment) motif, and dimethylated H4K20 (H4K2Ome2) with its TUDOR domain. One way BRCA1 (Breast cancer 1) is recruited to DSBs is through its interaction with RAP80 (receptor-associated protein 80), a protein that effectively binds K63-ub conjugates. BRCA1 has E3 ligase activity and functions as a heterodimer with BARD1 (BRCA1-associated RING domain protein 1). The DUBs BRCC36, $\mathrm{POH} 1$, and OTUB2 regulate DDR signaling by hydrolyzing DSB-induced K63-ub chains. OTUB2 also opposes to RNF8-dependent ubiquitination of L3MBTL1 (not shown). Whether MYSM1, which also possesses K63-ub cleavage activity, participates in this step of DDR is an open question. RNF168-mediated K27-linked ub chains on H2A/H2AX constitute additional DDR signals, and BRCA1/BARD1 catalyzed K6-linked chains (not shown) may also contribute to DDR. Specific activities that oppose to these atypical ub chains in DDR are not known. 53BP1 and BRCA1 determine effective DSB repair, with 53BP1 committing to NHEJ (non-homologous end joining) and BRCA promoting HR (homologous recombination). Dashed lines indicate proposed protein-protein interactions. $\mathrm{X}$ indicates an unknown RNF8 substrate(s), and $\mathrm{Y}$ and $\mathrm{W}$ indicate unknown RNF168 substrates. Please refer to the main text for details.

repressive complex 1 (PRC1) and is responsible for the monoubiquitination of $\mathrm{H} 2 \mathrm{~A}$ at the canonical site, Lys-K119 (yielding H2AK119ub), a histone mark that constitutes about $10-15 \%$ of H2A under physiological conditions (Goldknopf and Busch, 1977; Wang et al., 2004; Di Croce and Helin, 2013). While the major source of DSB-induced H2A poly-ubiquitination appears to be RNF8/RNF168-dependent (Lukas et al., 2011; Mattiroli et al., 2012), RING1b/BMI1 is required for silencing transcription in response to neighboring DSBs through local enhancement of H2A/H2AXK119ub (Ismail et al., 2010; Ginjala et al., 2011; 
Kakarougkas et al., 2014; Ui et al., 2015). RING1b/BMI1 is also thought to contribute to maintenance of active ATM at DSBs (Pan et al., 2011; Wu et al., 2011a). Interestingly, both ubiquitination of H2AK13/15ub by RNF168 and H2AK119ub by RING1b/BMI1 depend on an intact nucleosome acidic patch (Leung et al., 2014). It is proposed that this structure within $\mathrm{H} 2 \mathrm{~A} / \mathrm{H} 2 \mathrm{AX}$ serves as a scaffold to integrate differential signals on H2A (Leung et al., 2014). In contrast, the functional significance of H2AK127129 ub by the E3 BRCA1/BARD1 is still unclear (Kalb et al., 2014).

ATM-dependent mono-ubiquitination of histone H2B (H2BK120ub) also occurs in response to DSBs (Moyal et al., 2011; Nakamura et al., 2011). Similarly to H2A, H2B monoubiquitination fulfills a dual function, in gene transcription and in DDR (Shiloh et al., 2011). However, unlike H2AK119ub, $\mathrm{H} 2 \mathrm{BK} 120 \mathrm{ub}$ has been mostly linked to gene activation, in part through chromatin decompaction at transcribed regions (Shiloh et al., 2011; Fuchs and Oren, 2014). Transcriptional silencing and chromatin decondensation are both critical to ensure proper DNA repair. Given the physical proximity between H2BK120ub and $\mathrm{H} 2 \mathrm{AK} 13 / 15 \mathrm{ub}$ within the nucleosome, it is possible that these marks cooperate in the integration of these processes (Shiloh et al., 2011; Mattiroli et al., 2012; Jackson and Durocher, 2013). To this end, it is relevant the finding that RNF8 synergizes with its structurally related kinase CHFR (checkpoint with fork-head associated and ring finger) in $\mathrm{H} 2 \mathrm{~A}$ as well as $\mathrm{H} 2 \mathrm{~B}$ ubiquitination, an activity that promotes chromatin relaxation, ATM activation and genome stability in mice (Wu et al., 2011b).

DNA damage signaling and activation of DNA damage checkpoints result in transient cell-cycle arrest or permanent cell cycle withdrawal (Ciccia and Elledge, 2010). An important, yet not well-understood, aspect of ub-based DDR is how spatiotemporal control of the signaling is achieved. In particular, it remains to clarify in full how disassembly of the repair complexes occurs after the damage has been repaired, which enzymes are involved and how this impacts on termination of the DNA damage checkpoint, and ultimately on genomic stability and survival. Notably, excessive chromatin $\mathrm{ub}$ at DSBs associates with enhanced repair and spreading of gene silencing beyond the physiological boundaries, underscoring the relevance of tight control of this pathway (Gudjonsson et al., 2012). Consistently, several mechanisms have been discovered which modulate the magnitude of RNF8/RNF168-dependent ubiquitination, and regulatory inhibition has emerged as an integral DDR component (Panier and Durocher, 2013). Examples of such mechanisms include proteolytic ubiquitination of RNF168 (Gudjonsson et al., 2012), competition for recruitment of RNF168-dependent effectors by a RNF168 paralog (Panier et al., 2012; Poulsen et al., 2012), eviction of ubiquitinated proteins (Acs et al., 2011) and, as reviewed here, DUBs activities at multiple levels of the RNF8/RNF168 ubiquitination cascade.

\section{Modulation of DSB Signaling by DUBs}

Less then a decade ago, studies on the DUBs BRCC36, USP3 and USP16 first uncovered the importance of DUB activity in the modulation of ub-based DDR by regulating recruitment of RNF168-responsive factors, checkpoint recovery, and DSBinduced transcriptional silencing, respectively (Nicassio et al., 2007; Sobhian et al., 2007; Wang and Elledge, 2007; Doil et al., 2009; Shao et al., 2009; Shanbhag et al., 2010). Since then, an increasing body of evidence supports the reversal of DNA damage-induced chromatin ubiquitination by DUBs as a key aspect of the DSB response (Jackson and Durocher, 2013; Panier and Durocher, 2013). Indeed, siRNA-based screens in mammalian cells recently revealed that a great part of the DUB family has functional connections with the DSB response (Kato et al., 2014; Nishi et al., 2014; Yu et al., 2014) and a number of DUBs have been implicated as regulatory components of the RNF8 pathway (Table 1 and Figure 1). Recent findings have broadened the contribution of DUBs targeting histone $\mathrm{H} 2 \mathrm{~A}$, the critical RNF8-RNF168 substrate, to DDR, and will be the main focus of the next section.

\section{USP3}

The ub-specific protease USP3 is a chromatin-associated protein endowed with the ability of binding to ubiquitinated $\mathrm{H} 2 \mathrm{~A}$ through its Zn finger UBP domain (Nicassio et al., 2007). Biochemical and cellular studies showed that both $\mathrm{uH} 2 \mathrm{~A}$ and $\mathrm{uH} 2 \mathrm{~B}$ are relevant USP3 targets (Nicassio et al., 2007; Mosbech et al., 2013). We recently found that deletion of Usp3 in mice leads to a measurable increase in $\mathrm{uH} 2 \mathrm{~A}$ and $\mathrm{uH} 2 \mathrm{~B}$ in freshly isolated tissues, suggesting that USP3 has a non-redundant role in preventing accumulation of $\mathrm{uH} 2 \mathrm{~A}$ and $\mathrm{uH} 2 \mathrm{~B}$ in vivo (Lancini et al., 2014). USP3 is implicated in the regulation of S-phase progression (Nicassio et al., 2007), a role that may be relevant also in the context of HSC biology (see below; Lancini et al., 2014), and in the DSB response. Removal of the ub mark by USP3 appears important for the prevention and/or for proper repair of spontaneous DNA damage as well as for DSB repair and resolution of DDR signaling upon clastogeninduced DSBs (Nicassio et al., 2007; Lancini et al., 2014; Nishi et al., 2014). In line with a role for USP3 in the DSB response, Usp3-deleted HSCs and mice are hypersensitive to IR (Lancini et al., 2014). Mechanistically, the data suggest that USP3 limits the RNF8/RNF168 pathway by reversing the ubiquitination catalyzed by these ligases. In fact, ectopic expression of wild-type USP3, but not a catalytically inactive mutant protein, prevented accumulation of RNF168 and 53BP1 at IR-induced DNA damage foci (IRIFs), while leaving upstream signaling through $\gamma \mathrm{H} 2 \mathrm{AX}$ and RNF8 intact (Doil et al., 2009; Mosbech et al., 2013). Notably, RNF8 also ubiquitinates non-histone proteins at DSBs (Acs et al., 2011; Meerang et al., 2011; Mallette et al., 2012) and RNF8-catalyzed ub conjugates distinct form $\mathrm{H} 2 \mathrm{~A} / \mathrm{H} 2 \mathrm{AX}$ are required for RNF168 recruitment (Mattiroli et al., 2012). Given the excess of chromatin-bound $\mathrm{ub}$ conjugates compared to the increase of uH2A measured upon USP3 loss (Nicassio et al., 2007; Lancini et al., 2014), it is conceivable that modulation of DDR signaling by USP3 may involve deubiquitination of additional, non-histone, targets. Because of spatial proximity, it is possible that these other USP3 targets may include as-yet undefined RNF8 substrates and/or DDR factors, many of which are known to be ubiquitinated, including RNF168 and 53BP1 
TABLE 1 | Mammalian DUBs that have been associated with the chromatin-based DSB response and their implications in organism physiology and human disease.

\begin{tabular}{|c|c|c|c|c|c|}
\hline DUB & Substrate(s) & $\begin{array}{l}\text { Proposed role(s) in } \\
\text { DDR }\end{array}$ & $\begin{array}{l}\text { Other cellular } \\
\text { functions }\end{array}$ & $\begin{array}{l}\text { Implications in organism } \\
\text { physiology/disease }\end{array}$ & Reference \\
\hline \multicolumn{6}{|c|}{ Ubiquitin specific proteases (USP) } \\
\hline USP3 & $\begin{array}{l}\mathrm{H} 2 \mathrm{~A}, \mathrm{H} 2 \mathrm{AX} \\
\mathrm{H} 2 \mathrm{~B}, \mathrm{RIG} 1\end{array}$ & $\begin{array}{l}\text { Antagonizes RNF168 } \\
\text { IRIFs; promotes, DSB } \\
\text { repair, } \\
\text { sensitization:IR }{ }^{1}\end{array}$ & $\begin{array}{l}\text { Cell cycle; type I } \\
\text { interferon signaling; } \\
\text { HGF-dependent } \\
\text { scattering response }\end{array}$ & $\begin{array}{l}\text { Usp3-null mice display lymphopenia, } \\
\text { decline in HSC function and } \\
\text { spontaneous tumorigenesis upon aging }\end{array}$ & $\begin{array}{l}\text { Nicassio et al. (2007), Buus et al. } \\
\text { (2009), Doil et al. (2009), Mosbech et al } \\
\text { (2013), Cui et al. (2014), Lancini et al. } \\
\text { (2014), Nishi et al. (2014), Sharma et al. } \\
\text { (2014) }\end{array}$ \\
\hline $\begin{array}{l}\text { USP16/ } \\
\text { Ubp-M }\end{array}$ & $\mathrm{H} 2 \mathrm{~A}^{2}$ & $\begin{array}{l}\text { DSB-induced gene } \\
\text { silencing }\end{array}$ & $\begin{array}{l}\text { Cell cycle; } \\
\text { transcription; ESC } \\
\text { differentiation }\end{array}$ & $\begin{array}{l}\text { Usp16 knockout is embryonic lethal. } \\
\text { Trisomy of Usp16 (Ts65Dn model for } \\
\text { Down's syndrome) associates with } \\
\text { reduced HSC self-renewal }\end{array}$ & $\begin{array}{l}\text { Joo et al. (2007), Shanbhag et al. } \\
\text { (2010), Adorno et al. (2013), Yang et al. } \\
\text { (2014), Zhang et al. (2014) }\end{array}$ \\
\hline $\begin{array}{l}\text { Dub3/ } \\
\text { USP17L2 }\end{array}$ & $\begin{array}{l}\mathrm{H} 2 \mathrm{AX} \\
\text { Cdc25A }\end{array}$ & $\begin{array}{l}\text { Antagonizes RNF168 } \\
\text { IRIFs }\end{array}$ & $\begin{array}{l}\text { Cell cycle/DNA } \\
\text { damage checkpoint; } \\
\text { ESC self-renewal }\end{array}$ & $\begin{array}{l}\text { Promotes growth of human breast } \\
\text { cancer xenograft tumors }\end{array}$ & $\begin{array}{l}\text { Pereg et al. (2010), van der Laan et al. } \\
\text { (2013), Delgado-Diaz et al. (2014) }\end{array}$ \\
\hline USP34 & RNF168, Axin & $\begin{array}{l}\text { Stabilizes RNF168 } \\
\text { protein }\end{array}$ & $\begin{array}{l}\text { Wnt/beta-catenin } \\
\text { signaling }\end{array}$ & n.d. & Lui et al. (2011), Sy et al. (2013) \\
\hline USP44 & $\begin{array}{l}\mathrm{H} 2 \mathrm{~A}, \mathrm{H} 2 \mathrm{~B} \\
\mathrm{CDC} 20\end{array}$ & $\begin{array}{l}\text { Antagonizes RNF168 } \\
\text { and 53BP1 IRIFs }\end{array}$ & $\begin{array}{l}\text { Spindle assembly } \\
\text { checkpoint; prevents } \\
\text { aneuploidy }\end{array}$ & $\begin{array}{l}\text { Usp44-null mice develop spontaneous } \\
\text { tumors, in particular in the lung }\end{array}$ & $\begin{array}{l}\text { Stegmeier et al. (2007), Song et al. } \\
\text { (2010), Zhang et al. (2011, 2012), } \\
\text { Fuchs et al. (2012), Mosbech et al. } \\
\text { (2013) }\end{array}$ \\
\hline \multicolumn{6}{|c|}{ Ubiquitin C-terminal hydrolases (UCH) } \\
\hline BAP1 & $\begin{array}{l}\text { H2AK119ub } \\
\text { H2AX }\end{array}$ & $\begin{array}{l}\text { Promotes DSB repair. } \\
\text { Sensitization: IR and } \\
\text { PARP inhibitors }\end{array}$ & $\begin{array}{l}\text { Cell cycle progression; } \\
\text { transcription }\end{array}$ & $\begin{array}{l}\text { Bap1-knockout is embryonic lethal; } \\
\text { Bap1 deletion in adulthood results in } \\
\text { HSC defects and myeloid } \\
\text { transformation. Human tumor } \\
\text { suppressor }\end{array}$ & $\begin{array}{l}\text { Nishikawa et al. (2009), Harbour et al. } \\
\text { (2010), Scheuermann et al. (2010), Bott } \\
\text { et al. (2011), Dey et al. (2012), } \\
\text { Peña-Llopis et al. (2012), Carbone et al. } \\
\text { (2013), Ismail et al. (2014), Nishi et al. } \\
\text { (2014), Yu et al. (2014) }\end{array}$ \\
\hline \multicolumn{6}{|c|}{ JAMM/MPM+ metallo-proteases } \\
\hline $\begin{array}{l}\text { BRCC36, } \\
\text { (BRCC3) }\end{array}$ & $\begin{array}{l}\text { K63-ub, } \\
\text { H2A-K63-ub, } \\
\text { IFNAR1 }\end{array}$ & $\begin{array}{l}\text { Restrict DNA end } \\
\text { resection; limits HR. } \\
\text { Sensitization: IR }\end{array}$ & Interferon responses & $\begin{array}{l}\text { Aberrant expression in human breast } \\
\text { tumors }\end{array}$ & $\begin{array}{l}\text { Dong et al. (2003), Sobhian et al. } \\
\text { (2007), Wang and Elledge (2007), } \\
\text { Cooper et al. (2009), Shao et al. (2009), } \\
\text { Coleman and Greenberg (2011), Hu } \\
\text { et al. (2011), Zheng et al. (2013) }\end{array}$ \\
\hline $\begin{array}{l}\text { MYSM1/ } \\
\text { 2A-DUB }\end{array}$ & $\mathrm{H} 2 \mathrm{~A}$ & $\begin{array}{l}\text { Promotes DSB repair. } \\
\text { Sensitization: } \mathbb{I R}^{1}\end{array}$ & Transcription & $\begin{array}{l}\text { Mysm1-null mice display partial } \\
\text { embryonic lethality, growth retardation, } \\
\text { epidermal abnormalities, multi-lineage } \\
\text { hematopoietic defects, HSC } \\
\text { deficiencies and predisposition to } \\
\text { lymphoma }\end{array}$ & $\begin{array}{l}\text { Zhu et al. (2007), Jiang et al. (2011), } \\
\text { Nijnik et al. (2012), Nandakumar et al. } \\
\text { (2013), Wang et al. (2013), DiTommaso } \\
\text { et al. (2014), Liakath-Ali et al. (2014), } \\
\text { Nishi et al. (2014), Won et al. (2014), } \\
\text { Belle et al. (2015), Gatzka et al. (2015) }\end{array}$ \\
\hline $\begin{array}{l}\text { POH1/ } \\
\text { PSMD14 }\end{array}$ & K63-ub & $\begin{array}{l}\text { Restricts 53BP1; } \\
\text { promotes RAD51; } \\
\text { sensitization: IR, } \\
\text { cis-platin, HU }\end{array}$ & Proteasome activity & n.d. & $\begin{array}{l}\text { Yao and Cohen (2002), Butler et al. } \\
\text { (2012), Kakarougkas et al. (2013) }\end{array}$ \\
\hline \multicolumn{6}{|c|}{ Ovarian tumor proteases (OTU) } \\
\hline OTUB1 & K48-ub & $\begin{array}{l}\text { Non-catalytical } \\
\text { inhibition of RNF168 } \\
\text { and of } \\
\text { K63-ub-chains. } \\
\text { Sensitization:IR }\end{array}$ & $\begin{array}{l}\text { p53 stability; TGF } \beta \\
\text { signaling; c-IAP1 } \\
\text { stability }\end{array}$ & n.d. & $\begin{array}{l}\text { Nakada et al. (2010), Juang et al. } \\
\text { (2012), Sun et al. (2012), Wiener et al. } \\
\text { (2012), Herhaus et al. (2013), Mevissen } \\
\text { et al. (2013) }\end{array}$ \\
\hline OTUB2 & $\begin{array}{l}\text { L3MBTL1, } \\
\text { K63-ub }\end{array}$ & $\begin{array}{l}\text { Suppresses HR, } \\
\text { sensitization:NCS and } \\
\text { CPT }\end{array}$ & n.d. & n.d. & Kato et al. (2014) \\
\hline
\end{tabular}

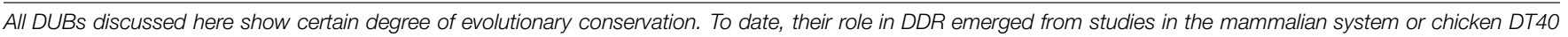

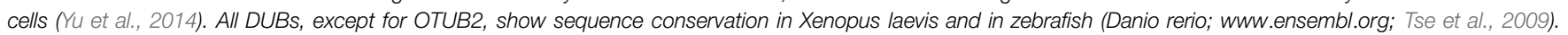

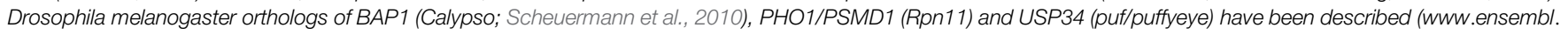

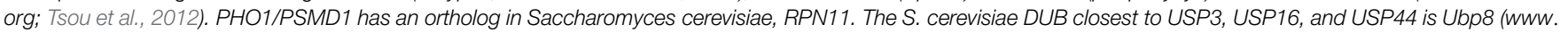

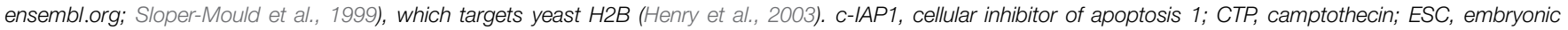

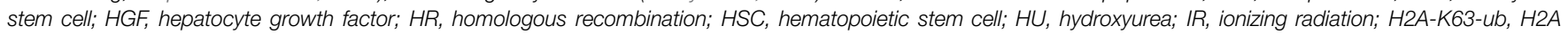

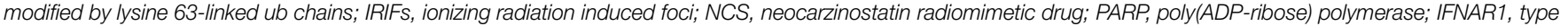

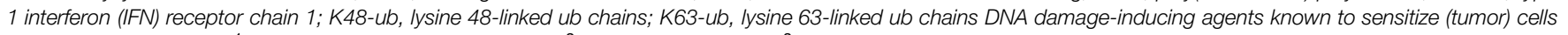
depleted for the DUB or ${ }^{1}$ DUB knockout mice are indicated; ${ }^{2}$ not H2B, not K63-ub; ${ }^{3}$ not H2A-K63-ub. n.d., not determined. 
(Gudjonsson et al., 2012; Jackson and Durocher, 2013). In this regard, it is of note that ectopic green fluorescent protein (GFP)USP3 fusion protein could not be detected at DNA damage foci (Mosbech et al., 2013). While this may reflect detection limitations liked to the experimental conditions, it is also possible that USP3 may, at least in part, act in DDR through indirect mechanisms.

\section{USP16}

By a conventional chromatography approach, USP16 (also known as Ubp-M) was purified from HeLa cells as an enzyme strongly active in removing the mono-ub moiety form $\mathrm{H} 2 \mathrm{~A}$ (Joo et al., 2007). Consistently, growing evidence support a functional role of USP16 in counteracting PcG-mediated gene silencing through H2AK119ub deubiquitination (Joo et al., 2007; Adorno et al., 2013; Frangini et al., 2013; Yang et al., 2014). Local transcription inhibition also occurs in cis at the chromatin contiguous to sites of DSB induction, a phenomenon dependent on the ATM/RNF8/RNF168 ub pathway (Shanbhag et al., 2010) and on RING1b/BMI1 (Kakarougkas et al., 2014; Ui et al., 2015). Notably, siRNA-mediated knock- down of Usp16 expression resulted in sustained DSB-induced $\mathrm{uH} 2 \mathrm{~A}$, which prolonged gene silencing in the proximity of the DSB (Shanbhag et al., 2010). These findings implicate USP16 in controlling reversible transcriptional inhibition at DSBs by removal of $\mathrm{uH} 2 \mathrm{~A}$ and place USP16 at the interplay between DDR signaling and local gene silencing (Shanbhag et al., 2010). Whether USP16 impacts on DSB repair is unclear. In fact, USP16 was not readily detected at IRIFs and its ectopic expression failed to limit 53BP1 recruitment at DSBs (Mosbech et al., 2013; Nishi et al., 2014). Also, USP16 did not score above significance in a siRNA-based in vitro functional screen for DUBs affecting spontaneous DNA damage, DSB repair or DSB-induced G2/M checkpoint (Nishi et al., 2014). Recently, USP16 has been found to interact with HERC2 (Sowa et al., 2009; Zhang et al., 2014), an E3 ligase known to stabilize the RNF8 interaction with its cognate E2 ubc13 and to promote DSB signaling (Bekker-Jensen et al., 2010). This finding puts forward a potential mechanism through which USP16 may be implicated in the RNF8 pathway.

\section{USP44}

Functional genetic screens first uncovered USP44 as a regulator of the mitotic spindle assembly checkpoint through deubiquitination of the APC activating subunit CDC20 (Stegmeier et al., 2007; Song et al., 2010). Further establishing USP44 function during mitosis, a genetic approach revealed the requirement of USP44 for proper centrosome separation and positioning, ensuring accurate chromosome segregation (Zhang et al., 2012). More recently, an overexpression screen for DUBs antagonizing the RNF8-RNF168 pathway was performed in human U2OS cells. Among the 60 DUBs tested, USP44 was identified as one of the five DUBs that potently abrogate recruitment of 53BP1 to IRIFs, along with the previously identified USP3 (Nicassio et al., 2007; Doil et al., 2009) and OTUB1 (Nakada et al., 2010; Mosbech et al., 2013). Consistent with such an activity, GFP-USP44 re-localized to DNA damage sites generated by laser micro-irradiation, in a manner dependent on RNF8 and RNF168 (Mosbech et al., 2013; Nishi et al., 2014). Direct reversal of $\mathrm{H} 2 \mathrm{~A}$ ubiquitination is likely one of the inhibitory mechanisms through which USP44 opposes to 53BP1 recruitment. In fact, inducible expression of wild type USP44 was accompanied by: (i) strong reduction of cellular $\mathrm{uH} 2 \mathrm{~A}$, indicating that USP44 can target the most abundant H2AK119ub mark; (ii) reduction of mono- di- and tri-ub $\mathrm{H} 2 \mathrm{~A}$ upon $\mathrm{H} 2 \mathrm{~A}$ co-overexpression, a condition that allows visualization of poly-ub chains; (iii) displacement of endogenous RNF168 from IRIFs. USP44 displays certain specificity for histones and can target, besides $\mathrm{uH} 2 \mathrm{~A}, \mathrm{uH} 2 \mathrm{~B}$ (Mosbech et al., 2013), an activity that may also contribute to DDR (Shiloh et al., 2011). These findings are in line with USP44 being a chromatin-associated protein (Stegmeier et al., 2007; Fuchs et al., 2012) and with the identification of $\mathrm{H} 2 \mathrm{~A}$ and $\mathrm{H} 2 \mathrm{~B}$ as significantly enriched interactors in a proteomics survey (Sowa et al., 2009).

Notably, USP44 shares with USP3 the ability to target both $\mathrm{uH} 2 \mathrm{~A}$ and $\mathrm{uH} 2 \mathrm{~B}$ and to displace RNF168 and 53BP1 from IRIFs (Nicassio et al., 2007; Doil et al., 2009; Fuchs et al., 2012; Mosbech et al., 2013). This suggests that these DUBs may have related/overlapping functions in DDR, a hypothesis also supported by their clustering in phylogenetic analysis of DUBs based on DSB repair activity (Nishi et al., 2014). One could envisage temporal or spatial regulation of the activities of these DUBs in relation to different chromatin territories at the DSB (Chapman et al., 2012; Kakarougkas et al., 2013), cell cycle or chromatin states. It is currently not known if their effects on $\mathrm{uH} 2 \mathrm{~A} / \mathrm{uH} 2 \mathrm{~B}$ are additive. USP3 knock-down alone causes a significant, although modest, enlargement of spontaneous and IR induced 53BP1 foci (Nicassio et al., 2007; Gudjonsson et al., 2012). The engagement of USP3 and USP44 potentially similar activities at DSBs may reflect the need to effectively control RNF168-mediated signaling. It will be interesting to address this interplay and to investigate how USP44 impacts on genomic stability and cellular survival upon damage.

\section{BAP1}

The BRCA1-associated protein 1 (BAP1; also known as UCHL2) displays DUB activity for H2AK119ub (Scheuermann et al., 2010). BAP1 is active in the context of the PcG repressive complex PR-DUB, an evolutionary conserved complex comprising BAP1 and additional sex combs-like 1 (ASXL1) in mammals, and their orthologs Calypso and Asx in Drosophila (Scheuermann et al., 2010). The Drosophila PR-DUB complex is thought to maintain a balanced H2AK119ub status required for proper HOX gene silencing (Scheuermann et al., 2010). Consistent with functional conservation, BAP1 interaction with ASLX1 and functional implication in PcG target genes regulation are documented in mammalian cells (Bott et al., 2011; Dey et al., 2012; Peña-Llopis et al., 2012). In addition, a number of studies implicate BAP1 in the DSB response. Indeed, shRNA-mediated silencing/loss of Bapl results in defective DSB repair (Nishi et al., 2014; Yu et al., 2014) and Bap1-null cancer cell-lines are hypersensitive to IR (Nishikawa et al., 2009; Bott et al., 2011; Peña-Llopis et al., 2012; Ismail et al., 2014; Yu et al., 2014). Experimental evidence of chromatin recruitment based on 
chromatin immunoprecipitation (ChIP) at I-Sce-induced breaks (Yu et al., 2014) and visualization by microscopy at sites of microirradiation (Ismail et al., 2014; Nishi et al., 2014) suggests that BAP1 function is exerted at the chromatin flanking DBSs. In fact, enhancement of $\mathrm{uH} 2 \mathrm{~A} / \mathrm{uH} 2 \mathrm{AX}$ levels upon IR was reported upon BAP1 depletion (Ismail et al., 2014; Yu et al., 2014). Since BAP1 is recruited to DSBs together with its PcG protein partner ASLX (Ismail et al., 2014), one potential function of the PR-DUB might be regulation of (PcG-mediated) transcriptional silencing at DSBs (Shanbhag et al., 2010; Kakarougkas et al., 2014; Ui et al., 2015). It will be interesting to further investigate the interplay between BAP1 and the PcG repressive complexes PRC1 and PRC2 at DBS.

Similarly to BRCA1-loss, BAP1-deficient cells show hypersensitivity to PARP inhibition, a finding that suggests involvement of BAP1 in BRCA-mediated HR (Peña-Llopis et al., 2012; Ismail et al., 2014; Yu et al., 2014). In support of this hypothesis, Ismail et al. (2014) and Yu et al. (2014) reported reduced recruitment of BRCA1 and of key HR factors such as RAD51 and RPA at damage sites, concomitant with defective HR. The cellular interplay between BAP1 and BRCA1 is, however, far from being understood. On one hand, BAP1 was first discovered in a yeast two-hybrid screen as a BRCA1-interacting protein (Jensen et al., 1998). On the other, proteomic studies in human/mouse cells did not detect BAP1 in stable complex with BRCA1 (Sowa et al., 2009; Bott et al., 2011; Dey et al., 2012). In vitro, BAP1 antagonizes the ub ligase activity of the BRCA1/BARD1 complex (Nishikawa et al., 2009), this being the E3 complex with DDR functions (Greenberg et al., 2006). If this would hold in vivo, BAP1 may be important to regulate BRCA1/BARD1 activity and/or it may target putative/yetundefined BRCA1 substrates during DDR (Kalb et al., 2014). Identifications of BAP1 targets during DDR will aid in clarifying whether BAP1-mediated regulation of BRCA1 activity is a mechanism to control HR.

Further, connecting BAP1 to PARP, it is of note that recruitment of GFP-BAP1 to laser-induced DSBs requires PARP activity, beside RNF8/RNF168 (Ismail et al., 2014). However, since BAP1 does not seem to bind directly to poly(ADP) ribose (PAR) polymers, PARP effect on BAP1 in DDR has been suggested to be indirect (Ismail et al., 2014). PARP has been reported to promote RNF168-mediated DDR signaling and repair (Smeenk et al., 2013), as well as it has been implicated in favoring recruitment of PcG proteins (MEL18 and CBX4) to DSBs (Chou et al., 2010). Also, the RNF8-related E3 CHFR, which appears to regulate the first wave of ubiquitination, requires PAR for its rapid recruitment to DSBs (Liu et al., 2013). Most likely, the link between PARP and BAP1 in DDR is among one of these activities.

\section{MYSM1/2A-DUB}

The metalloprotease MYSM1 (also known as 2A-DUB) deubiquitinates $\mathrm{uH} 2 \mathrm{~A}$ in vitro and in cell lines (Zhu et al., 2007). Although it was originally identified as a transcriptional co-activator (Zhu et al., 2007), recent findings connect this DUB to DDR. MYSM1 has a distinctive domain architecture among the DUBs, harboring a SANT and SWIRM domains, which are frequently found in transcription factors and in DNA/chromatinassociated proteins (Boyer et al., 2004; Yoneyama et al., 2007). Consistently, ChIP assays detected enrichment of MYSM1 at numerous gene promoters (Zhu et al., 2007; Jiang et al., 2011; Wang et al., 2013). Interestingly, MYSM1 is also capable of binding to DSBs flanking chromatin, where it may favor repair (Nishi et al., 2014). Further linking MYSM1 to DDR, MYSM1 was identified as an ATM phosphorylation target upon damage (Matsuoka et al., 2007) and its deletion in mice confers sensitivity to total body IR (Wang et al., 2013). Spontaneous DNA damage may also be enhanced upon MYSM1 loss, as measured by increased $\gamma \mathrm{H} 2 \mathrm{AX}$ staining, micronuclei and oxidative stress in hematopoietic populations of MYSM-deficient mice (Nijnik et al., 2012; Gatzka et al., 2015). Yet, MYSM1 involvement in DDR and more specifically in the RNF8 pathway remains largely unexplored. MYSM1 activity has been mostly linked to the repressive mark H2AK119ub (Zhu et al., 2007; Jiang et al., 2011; Wang et al., 2013; Won et al., 2014), opening the possibility of MYSM1 participation in regulating DSB-induced gene silencing. Also, rather than targeting the DDR H2AK13/15ub mark (Mosbech et al., 2013), MYSM1 may, similarly to other JAMM/MPN+ metalloproteases (see below), display specificity for Lys63-linked ub chains (Komander et al., 2009), which are key DDR signals.

Finally, with regards to $\mathrm{H} 2 \mathrm{~A}$ DUBs, another DUB that has been reported to oppose to $\mathrm{H} 2 \mathrm{AX}$ ubiquitination, thereby preventing recruitment of both $53 \mathrm{BP} 1$ and BRCA1 to DSBs is DUB3 (Delgado-Diaz et al., 2014). At least five additional DUBs can limit RNF8-RNF168-mediated chromatin ubiquitination. These DUBs are more extensively reviewed elsewhere (Jackson and Durocher, 2013; Panier and Durocher, 2013). Among these, BRCC36 (BRCC3), POH1/PSMD14 and OTUB1 directly target $\mathrm{ub}$ conjugates on chromatin. The JAMM/MPN(+) DUBs BRCC36 (BRCC3; Dong et al., 2003; Sobhian et al., 2007; Shao et al., 2009) and POH1/PSMD14 (Butler et al., 2012) act as negative regulators by displaying selectivity for K63-ub at DSBs. BRCC36 is part of the BRCA1-A complex and, together with Rap80, has been associated with inhibition of HR early upon DSB induction (Coleman and Greenberg, 2011; Hu et al., 2011). On the other hand, one of the reported functions of the $19 \mathrm{~S}$ proteasome subunit POH1 is to promote HR, supporting contribution of DUB activity to DSB repair pathway choice (Butler et al., 2012; Kakarougkas et al., 2013). Further in line with such hypothesis, depletion of the otubain family DUB OTUB2 resulted in decreased $\mathrm{HR}$, as measured by the DR-GFP HR reporter assay (Kato et al., 2014). OTUB2 is thought to act early after damage by preventing RNF8-mediated ubiquitination of L3MBTL1, which proteasomal degradation is required for 53BP1 recruitment (Acs et al., 2011), as well as K63-ub (Kato et al., 2014). However, unlike for BRCC36, these K63-ub-conjugates do not include $\mathrm{H} 2 \mathrm{~A}$, indicating the ability of these DUBs to target differential substrates (Shao et al., 2009; Kato et al., 2014). Notably, the DUBs OTUB1 and USP34 regulate DDR through indirect mechanisms. In fact, OTUB1 attenuates ub-based DDR through non-catalytic inhibition of RNF168 activity (Nakada et al., 2010). Instead, USP34 acts on RNF168 by removing 
degradative ub chains, thereby stabilizing the E3 and promoting DDR signaling (Sy et al., 2013). Also, indirect effects may underlie USP11 regulatory activity in HR (Wiltshire et al., 2010). Finally, USP28 is one more USP recruited via 53BP1 to DSBs. However, loss of USP28 did not cause significant DDR defects nor an altered phenotype in mice, indicating that this DUB does not have a prominent role in the DSB response (Knobel et al., 2014).

The substrate selectivity of the DUBs is critical is regulating DDR, given the diversity of ub signals at DSBs. Yet, how the DSB-associated H2A DUBs reach selectivity for H2AK119ub or H2AK13/15ub and if any of these DUBs can specifically oppose the DSB-induced H2AK13/15ub mark is still an open question. USP3 and USP44 potent activity toward steady state uH2A and their ability to limit 53BP1 IRIFs suggest that these DUBs can potentially target both the PcG-specific K119ub as well as the DDR-mediated K13/15ub marks on H2A (Nicassio et al., 2007; Doil et al., 2009; Mosbech et al., 2013; Sharma et al., 2014), the latter being a prerequisite for 53BP1 binding at damage sites (Fradet-Turcotte et al., 2013). Instead, USP16, BAP1 and MYSM1, lacking clear impact on 53BP1 IRIFs (Mosbech et al., 2013), may not be directly involved in H2AK13/15ub deubiquitination.

Notably, chromatin states are expected to impact on the recruitment/activity of the DUBs. In fact, MYSM1, which is found in complex with the histone acetyl transferase p/CAF, has been reported to be more active toward hyperacetylated nucleosomal substrates (Zhu et al., 2007). Also, recent ChIPsequencing approaches indicate that active transcription marks, such as $\mathrm{H} 3 \mathrm{~K} 36 \mathrm{Me} 3$, specify the recruitment of HR proteins to DSBs (Aymard et al., 2014), and readers of acetylated chromatin (bromodomain containing proteins) re-localize to DNA damage sites to promote gene silencing and repair by HR (Gong et al., 2015).

As to the "ubiquitin code," it is likely that, besides K48-, K63- and the less characterized K6-linked ub chains (Morris and Solomon, 2004), additional "atypical" ub polymers (Kulathu and Komander, 2012) participate in DSB signaling. Such examples are the recently reported K27-linked ub chains catalyzed by RNF168 on H2A/H2AX (Gatti et al., 2015). Also, K27-ub might be relevant for PcG-mediated DDR, as auto-ubiquitination of RING1B through mixed polyub chains (K6-K27-K48) is a prerequisite for its ability to mono-ubiquitinate $\mathrm{H} 2 \mathrm{~A}$ in vitro (Ben-Saadon et al., 2006). While a few DDR DUBs display ublinkage selectivity, such as the JAMM proteases BRCC36 and POH1 for K63-ub, OTUB1 for K48-ub and OTUB2 for K63ub (Butler et al., 2012; Komander and Rape, 2012; Mevissen et al., 2013; Kato et al., 2014), the ub-linkage selectivity of many other (DDR) DUBs is unclear. Potentially, DUBs belonging to the USP family can hydrolyze all linkages, al least when synthetic ub dimers are used as substrates in vitro (Faesen et al., 2011). Elucidation of DUB selectivity/regulation of activity in DDR awaits dedicated cell-based as well as in vitro assays, for example employing relevant substrates such as nucleosomal particles and (DDR-) specific E3/E2 ligases.
Finally, the ability to deubiquitinate multiple substrates is common within DUBs and the low degree of selectivity shown by the USPs in vitro suggests that other mechanisms rather than molecular substrate selection (i.e., regulation by cofactors, post-translational modifications, subcellular localization, cell cycle regulation) may have a greater role in determining their specificity in vivo (Komander et al., 2009; Clague et al., 2012; Sahtoe and Sixma, 2015). Indeed, for instance, BAP1 fails to deubiquitinate $\mathrm{H} 2 \mathrm{~A}$ if not in the context of the PR-DUB (Scheuermann et al., 2010). Similarly, the JAMM proteases POH1 and BRCC36 require protein-protein interactions for DUB activity and BRCC36 is targeted in the nucleus to DSBs or to cytoplasmatic functions by differential association with RAP80 or SHMT respectively (Cooper et al., 2009; Zheng et al., 2013). The use of catalytically inactive mutants that allows to circumvent the transient nature of the DUB/substrate interaction (Nicassio et al., 2007; Sowa et al., 2009), and conditions of DNA damage in proteomic approaches may help toward the identification of DUB targets/cofactors relevant for DSB signaling.

\section{DSBs-Associated DUBs: Implications in Stem Cell Maintenance and in Cancer}

De-regulation of DDR mechanisms can contribute to cancer but may also promote functional decline of the stem cells with consequential deterioration in tissue function and aging (Jackson and Bartek, 2009; Blanpain et al., 2011; Behrens et al., 2014). Consistent with this, recent studies uncovered the relevance of DSB-associated DUBs in preserving tissue function. Here, I will focus on the emerging roles of the H2A DUBs USP3, USP16, USP44, BAP1, and MYSM1 in HSC maintenance and cancer. The direct investigation of the consequences of inactivation of some of these DUBs has been so far restricted to HSCs for practical reasons. However, the recent advances in our understanding of stem cell niches in several organs warrant extending these studies to other tissues, which might uncover unique dependencies for individual components of the pathway.

\section{DSBs-Associated DUBs in Hematopoietic Stem Cell Biology}

Hematopoietic stem cells maintain homeostasis and replenish the blood system throughout life, by their ability to self-renew. DNA damage accumulates in HSCs during aging in mice and in man (Rossi et al., 2007; Rübe et al., 2011; Beerman et al., 2014), and it has become clear that genome repair is important for the HSC regenerative potential. In fact, DNA damage to the HSC pool has been identified as an underlying cause of BM failure in patients suffering from FA, an inherited DNA repair deficiency syndrome (Ceccaldi et al., 2012). In particular, a strong p53 response to replication stress and unresolved DNA damage was characterized as a critical mechanism for the progressive loss of HSCs and hence BM failure in FA patients (Ceccaldi et al., 2012). Further supporting a crucial role of DDR in HSC homeostasis, mouse models with engineered mutations in different DNA repair and DDR genes, besides FA related genes, manifest severe hematopoietic phenotypes and HSC deficiencies, in particular 
under conditions of stress (Ito et al., 2004; Nijnik et al., 2007; Rossi et al., 2007; Niedernhofer, 2008; Garaycoechea et al., 2012; Wang et al., 2012; Walter et al., 2015).

DNA damage, such as damage arising from inefficient DNA replication or from reactive oxygen species (ROS) and DSBs, can have two major consequences in HSCs. First, unrepaired DSBs may drive HSCs cell cycle arrest, senescence or apoptosis, or premature differentiation leading to their loss of function and consequent aging phenotypes and organ failure (Wang et al., 2012; Flach et al., 2014). Second, the accumulation of mutations providing selective advantage to the mutated cells can lead to cancer, as exemplified in myelodysplastic syndrome (MDS) and myelogenous leukemias (Blanpain et al., 2011; Behrens et al., 2014). Notably, the consequences of chronic genotoxic stress/persistent DNA damage signaling are mostly evident in tissues with high cell turnover and relying upon expansion of a limited number of stem/precursors cells, such as the hematopoietic system (Bender, 2002; Rossi et al., 2007). This makes the hematopoietic system potentially sensitive to even modest alterations in the ub-equilibrium in homeostasis as well as during ub-mediated DDR. An example in this direction is given by deletion of the DUB USP1 in mice. USP1 is a regulator of DNA-interstrand cross-links repair by the FA pathway through deubiquitination of one of its critical factor at the chromatin, FANCD2 (Kim et al., 2010). Consistent with such a role, USP1 deletion reduces the repopulation abilities of mouse HSCs (Parmar et al., 2010).

A link between the ub-based response to DSBs and HSC maintenance emerged from recent in vivo studies on USP3. Indeed, a clear pathological manifestation of Usp3 deletion in mice is progressive lymphopenia upon aging (Lancini et al., 2014). Such an altered lineage potential and immunodeficiency occur in the elderly and it has been linked to an impaired functional capacity of the aged HSCs (Geiger et al., 2013). Consistently with an age-dependent cellular attrition, USP3deficient HSCs displayed a marked decline in cell number and activity over time, as demonstrated in BM transplantation experiments (Lancini et al., 2014). Is this phenotype related to DNA damage? In support of this hypothesis, we found that USP3-deficient HSCs accumulate spontaneous DNA damage, are hypersensitive to IR in vivo and inefficiently resolve 53BP1 IRIFs and DSBs in vitro (Lancini et al., 2014). Collectively, these data suggest a role for USP3 in protecting the HSCs from DNA damage by restraining the ub-dependent DDR pathway (Lancini et al., 2014). Yet, the source of spontaneous DNA damage measured in USP3-deficient HSCs has not been identified. In absence of direct evidences, replication-associated genotoxic stress, which is thought to potently contribute to normal HSC decline during aging (Flach et al., 2014), may certainly be an accountable one. In fact, young USP3 knockout BM performed poorly in serial transplantations, a situation of enforced proliferation resembling what happens during aging (Lancini et al., 2014).

In line with an involvement of the RNF8-RNF168 pathway in hematopoiesis, inactivating mutations in RNF168 are associated with the RIDDLE syndrome, characterized by cellular radiosensitivity and immunodeficiency (Stewart et al., 2009), features which are recapitulated in knockout mouse models for these E3s (Li et al., 2010; Santos et al., 2010; Bohgaki et al., 2011). Whether RNF8/RNF168 deficiency also impact on HSC maintenance has not been reported, yet significant reduction of BM cellularity was measured upon RNF8 loss (Li et al., 2010). USP3 as well as RNF8 and RNF168-deficient mice constitute valuable in vivo models to gain insights into how lack of control of the ub-dependent DDR pathway may contribute to the functional decline observed in aged HSCs.

The Usp16 gene is located on human chromosome 21, a chromosome that is triplicated in Down's syndrome. Trisomy of Usp16 was recently associated with reduced HSC self-renewal in a mouse model for Down's syndrome (Ts65Dn), whose HSCs express 1.5-fold higher levels of Usp16 mRNA than wild type HSCs (Adorno et al., 2013). USP16 can deubiquitinate H2AK119ub (Joo et al., 2007), a critical mark for epigenetic control of stem-cell identity/maintenance and differentiation by the PcG E3 RING1B/BMI1 (Sparmann and van Lohuizen, 2006; Di Croce and Helin, 2013). Relevant to this review, BMI1 is essential to HSC self-renewal through mechanisms involving repression of the Cdkn2a tumor suppressor locus as well as protection from oxidative stress and DNA damage (Lessard and Sauvageau, 2003; Park et al., 2003; Liu et al., 2009). Notably, Adorno et al. (2013) linked increased Usp16 gene dosage with reduced $\mathrm{H} 2 \mathrm{~A}$ ubiquitination at the $C d k n 2 a$ locus and with a concomitant increase in senescence of Ts65Dn fibroblasts. This suggests that Usp16 trisomy contributes, at least in part, to the cellular defects of Ts65Dn mice through modulation of the BMI1 self-renewal and/or senescence pathway (Adorno et al., 2013). Increased ROS and markers of oxidative stress were also reported in Ts65Dn hematopoietic stem and progenitor cells (HSPCs) (Lorenzo et al., 2011). It will be interesting to investigate whether Usp16 trisomy contributes to this phenotype and whether Ts65Dn HSCs/fibroblasts suffer from augmented DNA damage/ DDR defects.

MYSM1, first linked to epigenetic control of B-cell development in mice (Jiang et al., 2011), recently emerged as a critical regulator of hematopoiesis. Notably, beside distinct multi-lineage defects in hematopoietic cell differentiation (Jiang et al., 2011; Nijnik et al., 2012; Nandakumar et al., 2013; Won et al., 2014), loss of MYSM1 in mice results in severe reduction of the HSC pool size and impairment in their in vivo repopulation capacity (Nijnik et al., 2012; Wang et al., 2013). While relative limited transcriptional changes were detected in Mysm1-null compared to wild type HSPCs, Gfil, one of the critical HSC factors, was identified as potential target for MYSM1-mediated epigenetic regulation (Wang et al., 2013). A consistent feature of Mysm1-null HSPCs that likely contributes to their reduced cellularity is an elevated apoptosis rate, accompanied by elevated ROS and $\gamma$ H2AX (Nijnik et al., 2012; Wang et al., 2013; Gatzka et al., 2015). Oxidative stress, accumulation of DNA damage and p53 activation are frequently associated with HSC deficiency and BM failure syndromes (Ito et al., 2004; Niedernhofer, 2008; Liu et al., 2009; Ceccaldi et al., 2012). Consistently, upregulation of p53 and of pro-apoptotic p53 target genes was measured in MYSM1-deficient cells (Nijnik et al., 2012; Belle et al., 2015; Gatzka et al., 2015) and p53 co-deletion significantly rescued 
HSCs numbers and activity in Mysm1-/-; p53-/- double mutant mice (Belle et al., 2015; Gatzka et al., 2015). As mentioned before, BMI1 plays a crucial role in protecting mouse cells, including HSCs, from mitochondrial dysfunction, ROS and DNA damage (Liu et al., 2009). Intriguingly, however, while antioxidants could rescue Bmi1-/- mice (Liu et al., 2009), similar treatments did not rescue Mysm1-/- mice developmental and hematopoietic phenotypes, suggesting that mechanisms other that oxidative stress may contribute to p53 activation in the context of MYSM1 loss (Belle et al., 2015). Further investigation of such p53-inducing cellular stresses and of MYSM1 links with DDR merits further studies. Perhaps relevant in this regard, Wang et al. (2013) reported exit from homeostatic quiescence for Mysm1-/- HSCs, a condition recently suggested to induce DNA damage and attrition in HSCs upon a range of physiological stresses (Walter et al., 2015). Notably, a homozygous truncating mutation in the MYSM1 gene was reported in two young siblings suffering form anemia, mild thrombocytopenia and lymphopenia, underlying its relevance in inherited BM failure disorders (Alsultan et al., 2013). Finally, induction and repair of programmed DSBs by NHEJ is a physiological process crucial for immune cells development (Alt et al., 2013). Whether DSB repair defects contribute to the developmental deficiencies reported in MYSM1-deficient B and T cells (Jiang et al., 2011; Nijnik et al., 2012; Gatzka et al., 2015) represent an interesting question for future investigation.

Dey et al. (2012) uncovered a novel role of BAP1 in HSC homeostasis. Indeed, BAP1 is expressed in the murine HSPC compartment and its deletion in adulthood resulted in skewing of differentiation toward the myeloid lineage and decreased HSC survival/self-renewal. BAP1 involvement in HSC function is intriguing and the effect of BAP1 loss on HSC quiescence, cell cycle progression and proliferative capacity warrant further investigation. While several genes including regulators of hematopoietic cell survival were identified as potential BAP1 targets in mouse HSPCs (Dey et al., 2012), it will be informative to address whether BAP1-deficient HSCs experience exacerbated DNA replication stress/DNA damage and/or DDR defects, which might contribute to their functional decline.

\section{DSBs-Associated DUBs in Cancer}

The importance of some of the previously mentioned factors in human cancer (e.g., BRCA1, 53BP1) underscores the impact of this pathway on human health (Jackson and Bartek, 2009; Gudjonsson et al., 2012). The analysis of RNF8- and RNF168deficient mice further supports a role of these key E3 ligases in tumor suppression (Li et al., 2010; Bohgaki et al., 2011). Notably, analogously to RNF8, Usp3-deleted mice develop a broad spectrum of tumor types with a latency of 1 year of age (Lancini et al., 2014). Such broad spontaneous neoplasia in USP3deficient mice might be linked to enhanced genomic instability, as observed in primary MEFs form these animals (Lancini et al., 2014). Further, MYSM1-deficient mice are tumor prone, developing thymic lymphoma with a latency of 4-6 months (Belle et al., 2015). Deletion of Usp16 in mice is instead early embryonic lethal and the consequences of its inactivation in adult tissues have not been explored (Yang et al., 2014). I will next focus on USP44 and BAP1, which have been best characterized as tumor suppressors in human pathology.

USP44 knockout mice are prone to develop spontaneous tumors, displaying in particular an approximately nine-fold increase in adenomas of the lung compared to wild type upon aging (Zhang et al., 2012). Notably, USP44 was also found frequently down-regulated in human bronchial adenocarcinomas and patients with low USP44 expression had significantly shorter overall survival, underscoring a tumor suppressive function in human cancer (Zhang et al., 2012). Zhang et al. (2012) reported that mouse cells lacking USP44 not only show a defect in silencing the mitotic checkpoint, a flaw linked to its deubiquitination activity toward the APC activating subunit CDC20 (Stegmeier et al., 2007), but they missegregate their chromosomes and exhibit whole chromosome aneuploidy (Zhang et al., 2012). These findings suggest that one mechanism by which USP44 suppresses tumorigenesis is by preventing aneuploidy, a feature commonly associated with human cancer (Zhang et al., 2012). Given USP44 novel implication in the control of DSB-induced chromatin ubiquitination, it is plausible that DDR defects may contribute to genomic instability and to the tumor prone phenotype of Usp44-/- mice (Mosbech et al., 2013). Moreover, USP44 has been reported to regulate gene expression and to prevent embryonic stem cell differentiation through $\mathrm{H} 2 \mathrm{~B}$ deubiquitination (Fuchs et al., 2012). It will be important to determine which of the functions of USP44 are critically required for tumor suppression.

BAP1 is an established tumor suppressor, with its genomic locus being frequently deleted in human cancer. In particular, prevalent somatic and germline BAP1 loss/inactivating mutations are found in metastatic uveal melanomas, malignant pleural mesothelioma and renal cell carcinomas (Harbour et al., 2010; Bott et al., 2011; Peña-Llopis et al., 2012; Carbone et al., 2013). The recent studies by Dey et al. (2012) revealed a potent tumor suppressive function of BAP1 also in myeloid neoplasia. This is supported by the observation that specific loss of Bap1 in mouse hematopoietic progenitors is sufficient for the propagation of features of human MDS upon transplantation and by the identification of de novo BAP1 mutations in MDS patients (Dey et al., 2012). The exact mechanism through which BAP1 regulates cell proliferation and tumorigenesis is not known and deciphering BAP1 functions is complicated by the diversity of protein (complexes) BAP1 interacts with in mammalian cells, these including PcG repressors (Bott et al., 2011; Dey et al., 2012; Peña-Llopis et al., 2012). Collectively, however, the current data based on quantitative analysis of BAP1 protein interactions and target genes identification implicate transcriptional de-regulation in the pathogenesis of BAP1-associated mesothelioma, renal cancer and myeloid neoplasia (Bott et al., 2011; Dey et al., 2012; Peña-Llopis et al., 2012). Consistently with a BAP1/PR-DUB functional role in PcG-mediated repression in Drosophila (Scheuermann et al., 2010), the complex BAP1-associated transcriptional network in mammals includes expression programs regulated by PcG proteins (Bott et al., 2011; Dey et al., 2012; 
Peña-Llopis et al., 2012), the genetic alteration of which predisposes to the development of various cancers (Sparmann and van Lohuizen, 2006; Di Croce and Helin, 2013).

As previously discussed, BAP1-deficient cancer cell lines were shown to be more sensitive to IR and to PARP inhibitors (PeñaLlopis et al., 2012; Ismail et al., 2014). Restoration with wild type BAP1, but not with catalytically inactive BAP1 or with mutant BAP1 mimicking cancer-associated mutations, protects the cells against genotoxic death (Peña-Llopis et al., 2012; Ismail et al., 2014). These studies indicates faults in DDR upon BAP1 loss and provide a platform to further investigate how (cancer-)inactivating mutations may affect BAP1-mediated DDR signaling/DSB repair and thereby contribute to tumor suppression. Of note, BAP1 is a substrate of the ATM/ATR checkpoint kinases, and it is phosphorylated upon several stressors, including IR, UV light and replication stress (Matsuoka et al., 2007; Eletr et al., 2013; Ismail et al., 2014; Yu et al., 2014). Therefore, pleotropic effects of BAP1 in DDR pathways can be expected.

Given the multiple roles of $\mathrm{uH} 2 \mathrm{~A}$, the consequences of deregulation of $\mathrm{H} 2 \mathrm{~A}$ targeting DUBs in vivo are complex and the field is confronted with the challenge of dissecting the molecular mechanisms involved. USP3 has been mainly linked to the DDR and does not appear to have a prominent role in gene expression (Lancini et al., 2014). Instead, while it is clear that USP16, BAP1, and MYSM1 can regulate gene transcription of, among others, PcG targets (Joo et al., 2007; Bott et al., 2011; Dey et al., 2012; Nijnik et al., 2012; Peña-Llopis et al., 2012; Adorno et al., 2013; Wang et al., 2013; Yang et al., 2014), the involvement of these DUBs in DDR has just emerged and the mechanism by which they contribute to genome stability is an important area for future studies.

Another critical question is the relevance of DDR-DUBs for human cancer. As discussed earlier, BAP1 is an established tumor suppressor in man. Also, Dub3 has oncogenic potential, a function that has been primarily related to its ability to regulate the crucial cell cycle regulator Cdc25A phosphatase (Pereg et al., 2010). As to the other DUBs discussed in this Review, crosscancer genetic alterations of the H2A-DUBs USP3, USP16, USP44 and MYSM1, as well as for BRCC36, OTUB1, OTUB2 have been reported (cBio Portal for cancer genomics, http://www. cbioportal.org/index.do; Dong et al., 2003). However, the role of these DUBs in human cancer remains to be elucidated.

\section{References}

Acs, K., Luijsterburg, M. S., Ackermann, L., Salomons, F. A., Hoppe, T., and Dantuma, N. P. (2011). The AAA-ATPase VCP/p97 promotes 53BP1 recruitment by removing L3MBTL1 from DNA double-strand breaks. Nat. Struct. Mol. Biol. 18, 1345-1350. doi: 10.1038/nsmb.2188

Adorno, M., Sikandar, S., Mitra, S. S., Kuo, A., Nicolis Di Robilant, B., Haro-Acosta, V., et al. (2013). Usp16 contributes to somatic stem-cell defects in Down's syndrome. Nature 501, 380-384. doi: 10.1038/nature 12530

Alsultan, A., Shamseldin, H. E., Osman, M. E., Aljabri, M., and Alkuraya, F. S. (2013). MYSM1 is mutated in a family with transient transfusion-dependent anemia, mild thrombocytopenia, and low NK- and B-cell counts. Blood 122, 3844-3845. doi: 10.1182/blood-2013-09-527127
Finally, RNF8/RNF168 amplification is frequently found in human tumors (TCGA, 2012) and RNF168 gain of function was connected with human papillomavirus (HPV)-positive cervical cancers (Gudjonsson et al., 2012). Lack of control of ub-mediated DDR signaling is a threat to genome integrity, and so potentially oncogenic, for instance during mitosis (Orthwein et al., 2014) and at telomeres, where the RNF8 pathway promotes illegitimate repair of chromosome ends (Peuscher and Jacobs, 2011). Notably, the role of DUBs in physiological inhibition of the RNF8 pathway at telomeres is emerging, with BRCC36 opposing to RNF168 to suppress chromosome end-to-end fusions (Okamoto et al., 2013).

\section{Concluding Remarks}

While it is clear that DUBs are critical regulators of the DSB response, we are only beginning to understand their molecular mechanisms of action, the consequences of their deregulation on genomic stability and their impact on organism physiology and human disease. A key unresolved question is the functional and molecular interplay between the DUBs in determining the ub-DDR cascade. Indeed, cooperation between DUBs-regulated functions likely occurs, and given the potential of functional compensation in vivo, such crosstalk is critical for genome maintenance and cell fate outcomes (Gudjonsson et al., 2012; Mosbech et al., 2013; Lancini et al., 2014; Nishi et al., 2014). Small-molecule inhibitors to DUBs are being developed with important achievements (Ernst et al., 2013; Jacq et al., 2013; Zhang and Sidhu, 2014). Gaining insights into DUBs functional roles and molecular networks in the DSB response could provide novel rationale for pursuing dedicated DUBs as drug targets.

\section{Acknowledgments}

I thank A. Duursma, G. Gargiulo, C. Lancini, and M. van Lohuizen for critical reading of the manuscript and useful discussion, and M. van Lohuizen for scientific support. I wish to apologize to all authors whose contribution could not be cited due to space limitations. Work in our lab is supported by grants form the Dutch Cancer Society (KWF; NKI-2012-5665) and by the Dutch Organization for Scientific Research NWO (Vidi 864.08.011; ASPASIA).

Alt, F. W., Zhang, Y., Meng, F.-L., Guo, C., and Schwer, B. (2013). Mechanisms of programmed DNA lesions and genomic instability in the immune system. Cell 152, 417-429. doi: 10.1016/j.cell.2013.01.007

Aymard, F., Bugler, B., Schmidt, C. K., Guillou, E., Caron, P., Briois, S., et al. (2014). Transcriptionally active chromatin recruits homologous recombination at DNA double-strand breaks. Nat. Struct. Mol. Biol. 21, 366-374. doi: 10.1038/nsmb.2796

Beerman, I., Seita, J., Inlay, M. A., Weissman, I. L., and Rossi, D. J. (2014). Quiescent hematopoietic stem cells accumulate DNA damage during aging that is repaired upon entry into cell cycle. Cell Stem Cell 15, 37-50. doi: 10.1016/j.stem.2014.04.016

Behrens, A., Van Deursen, J. M., Rudolph, K. L., and Schumacher, B. (2014). Impact of genomic damage and ageing on stem cell function. Nat. Cell Biol. 16, 201-207. doi: $10.1038 /$ ncb 2928 
Bekker-Jensen, S., Danielsen, J., Fugger, K., Gromova, I., Nerstedt, A., Bartek, J., et al. (2010). HERC2 coordinates ubiquitin-dependent assembly of DNA repair factors on damaged chromosomes. Nat. Cell Biol. 12, 80-86. doi: $10.1038 /$ ncb2008

Belle, J. I., Langlais, D., Petrov, J. C., Pardo, M., Jones, R. G., Gros, P., et al. (2015). p53 mediates loss of hematopoietic stem cell function and lymphopenia in Mysm1 deficiency. Blood 125, 2344-2348. doi: 10.1182/blood-2014-05-574111

Belle, J. I., and Nijnik, A. (2014). H2A-DUBbing the mammalian epigenome: expanding frontiers for histone $\mathrm{H} 2 \mathrm{~A}$ deubiquitinating enzymes in cell biology and physiology. Int. J. Biochem. Cell Biol. 50C, 161-174. doi: 10.1016/j.biocel.2014.03.004

Bender, C. (2002). Cancer predisposition and hematopoietic failure in Rad50S/S mice. Genes Dev. 16, 2237-2251. doi: 10.1101/gad.1007902

Ben-Saadon, R., Zaaroor, D., Ziv, T., and Ciechanover, A. (2006). The polycomb protein Ring1B generates self atypical mixed ubiquitin chains required for its in vitro histone H2A ligase activity. Mol. Cell 24, 701-711. doi: 10.1016/j.molcel.2006.10.022

Blanpain, C., Mohrin, M., Sotiropoulou, P. A., and Passegue, E. (2011). DNAdamage response in tissue-specific and cancer stem cells. Cell Stem Cell 8, 16-29. doi: 10.1016/j.stem.2010.12.012

Bohgaki, T., Bohgaki, M., Cardoso, R., Panier, S., Zeegers, D., Li, L., et al. (2011). Genomic instability, defective spermatogenesis, immunodeficiency, and cancer in a mouse model of the RIDDLE syndrome. PLoS Genetics 7:e1001381. doi: 10.1371/journal.pgen.1001381

Bott, M., Brevet, M., Taylor, B. S., Shimizu, S., Ito, T., Wang, L., et al. (2011). The nuclear deubiquitinase BAP1 is commonly inactivated by somatic mutations and 3p21.1 losses in malignant pleural mesothelioma. Nat. Genet. 43, 668-672. doi: $10.1038 /$ ng. 855

Bouwman, P., Aly, A., Escandell, J., Pieterse, M., Bartkova, J., Van Der Gulden, H., et al. (2010). 53BP1 loss rescues BRCA1 deficiency and is associated with triplenegative and BRCA-mutated breast cancers. Nat. Struct. Mol. Biol. 17, 688-695. doi: $10.1038 / \mathrm{nsmb} .1831$

Boyer, L. A., Latek, R. R., and Peterson, C. L. (2004). The SANT domain: a unique histone-tail-binding module? Nat. Rev. Mol. Cell Biol. 5, 158-163. doi: 10.1038/nrm1314

Brown, J. S., and Jackson, S. P. (2015). Ubiquitylation, neddylation and the DNA damage response. Open Biol. 5, 150018. doi: 10.1098/rsob.150018

Bunting, S. F., Callén, E., Wong, N., Chen, H., Polato, F., Gunn, A., et al. (2010). 53BP1 inhibits homologous recombination in Brcal-deficient cells by blocking resection of DNA breaks. Cell 141, 243-254. doi: 10.1016/j.cell.2010.03.012

Butler, L. R., Densham, R. M., Jia, J., Garvin, A. J., Stone, H. R., Shah, V., et al. (2012). The proteasomal de-ubiquitinating enzyme POH1 promotes the double-strand DNA break response. EMBO J. 31, 3918-3934. doi: 10.1038/emboj.2012.232

Buus, R., Faronato, M., Hammond, D. E., Urbe, S., and Clague, M. J. (2009). Deubiquitinase activities required for hepatocyte growth factorinduced scattering of epithelial cells. Curr. Biol. 19, 1463-1466. doi: 10.1016/j.cub.2009.07.040

Cao, L., Xu, X., Bunting, S. F., Liu, J., Wang, R., Cao, L. L., et al. (2009). A selective requirement for 53BP1 in the biological response to genomic instability induced by Brcal deficiency. Mol. Cell 35, 534-541. doi: 10.1016/j.molcel.2009.06.037

Carbone, M., Yang, H., Pass, H. I., Krausz, T., Testa, J. R., and Gaudino, G. (2013). BAP1 and cancer. Nat. Rev. Cancer 13, 153-159. doi: 10.1038/nrc3459

Ceccaldi, R., Parmar, K., Mouly, E., Delord, M., Kim, J. M., Regairaz, M., et al. (2012). Bone marrow failure in Fanconi anemia is triggered by an exacerbated p53/p21 DNA damage response that impairs hematopoietic stem and progenitor cells. Cell Stem Cell 11, 36-49. doi: 10.1016/j.stem.2012. 05.013

Chapman, J. R., Sossick, A. J., Boulton, S. J., and Jackson, S. P. (2012), BRCA1-associated exclusion of 53BP1 from DNA damage sites underlies temporal control of DNA repair. J. Cell Sci. 125, 3529-3534. doi: 10.1242/jcs. 105353

Chou, D., Adamson, B., Dephoure, N., Tan, X., Nottke, A., Hurov, K., et al. (2010). A chromatin localization screen reveals poly (ADP ribose)-regulated recruitment of the repressive polycomb and NuRD complexes to sites of DNA damage. Proc. Natl. Acad. Sci. U.S.A. 107, 18475-18480. doi: 10.1073/pnas.1012946107

Ciccia, A., and Elledge, S. J. (2010). The DNA damage response: making it safe to play with knives. Mol. Cell 40, 179-204. doi: 10.1016/j.molcel.2010.09.019
Clague, M. J., Coulson, J. M., and Urbe, S. (2012). Cellular functions of the DUBs. J. Cell Sci. 125, 277-286. doi: 10.1242/jcs. 090985

Coleman, K. A., and Greenberg, R. A. (2011). The BRCA1-RAP80 complex regulates DNA repair mechanism utilization by restricting end resection. J. Biol. Chem. 286, 13669-13680. doi: 10.1074/jbc.M110.213728

Cooper, E. M., Cutcliffe, C., Kristiansen, T. Z., Pandey, A., Pickart, C. M., and Cohen, R. E. (2009). K63-specific deubiquitination by two JAMM/MPN+ complexes: BRISC-associated Brcc36 and proteasomal Poh1. EMBO J. 28, 621-631. doi: 10.1038/emboj.2009.27

Cui, J., Song, Y., Li, Y., Zhu, Q., Tan, P., Qin, Y., et al. (2014). USP3 inhibits type I interferon signaling by deubiquitinating RIG-I-like receptors. Cell Res. 24, 400-416. doi: 10.1038/cr.2013.170

Delgado-Diaz, M. R., Martin, Y., Berg, A., Freire, R., and Smits, V. A. (2014). Dub3 controls DNA damage signalling by direct deubiquitination of H2AX. Mol. Oncol. 8, 884-893. doi: 10.1016/j.molonc.2014.03.003

Dey, A., Seshasayee, D., Noubade, R., French, D. M., Liu, J., Chaurushiya, M. S., et al. (2012). Loss of the tumor suppressor BAP1 causes myeloid transformation. Science 337, 1541-1546. doi: 10.1126/science.1221711

Di Croce, L., and Helin, K. (2013). Transcriptional regulation by Polycomb group proteins. Nat. Struct. Mol. Biol. 20, 1147-1155. doi: 10.1038/nsmb.2669

DiTommaso, T., Jones, L. K., Cottle, D. L., Gerdin, A. K., Vancollie, V. E., Watt, F. M., et al. (2014). Identification of genes important for cutaneous function revealed by a large scale reverse genetic screen in the mouse. PLoS Genet. 10:e1004705. doi: 10.1371/journal.pgen.1004705

Doil, C., Mailand, N., Bekker-Jensen, S., Menard, P., Larsen, D. H., Pepperkok, R., et al. (2009). RNF168 binds and amplifies ubiquitin conjugates on damaged chromosomes to allow accumulation of repair proteins. Cell 136, 435-446. doi: 10.1016/j.cell.2008.12.041

Dong, Y., Hakimi, M., Chen, X., Kumaraswamy, E., Cooch, N., Godwin, A., et al. (2003). Regulation of BRCC, a holoenzyme complex containing BRCA1 and BRCA2, by a signalosome-like subunit and its role in DNA repair. Mol. Cell 12, 1087-1099. doi: 10.1016/S1097-2765(03)00424-6

Eletr, Z. M., Yin, L., and Wilkinson, K. D. (2013). BAP1 is phosphorylated at serine 592 in S-phase following DNA damage. FEBS Lett. 587, 3906-3911. doi: 10.1016/j.febslet.2013.10.035

Ernst, A., Avvakumov, G., Tong, J., Fan, Y., Zhao, Y., Alberts, P., et al. (2013). A strategy for modulation of enzymes in the ubiquitin system. Science 339, 590-595. doi: 10.1126/science.1230161

Faesen, A. C., Luna-Vargas, M. P., Geurink, P. P., Clerici, M., Merkx, R., Van Dijk, W. J., et al. (2011). The differential modulation of USP activity by internal regulatory domains, interactors and eight ubiquitin chain types. Chem. Biol. 18, 1550-1561. doi: 10.1016/j.chembiol.2011.10.017

Flach, J., Bakker, S. T., Mohrin, M., Conroy, P. C., Pietras, E. M., Reynaud, D., et al. (2014). Replication stress is a potent driver of functional decline in ageing haematopoietic stem cells. Nature 512, 198-202. doi: 10.1038/nature 13619

Fradet-Turcotte, A., Canny, M. D., Escribano-Diaz, C., Orthwein, A., Leung, C. C., Huang, H., et al. (2013). 53BP1 is a reader of the DNA-damage-induced H2A Lys 15 ubiquitin mark. Nature 499, 50-54. doi: 10.1038/nature12318

Frangini, A., Sjoberg, M., Roman-Trufero, M., Dharmalingam, G., Haberle, V. Bartke, T., et al. (2013). The aurora B kinase and the polycomb protein ring1B combine to regulate active promoters in quiescent lymphocytes. Mol. Cell 51, 647-661. doi: 10.1016/j.molcel.2013.08.022

Fuchs, G., and Oren, M. (2014). Writing and reading H2B monoubiquitylation. Biochim. Biophys. Acta 1839, 694-701. doi: 10.1016/j.bbagrm.2014. 01.002

Fuchs, G., Shema, E., Vesterman, R., Kotler, E., Wolchinsky, Z., Wilder, S., et al. (2012). RNF20 and USP44 regulate stem cell differentiation by modulating H2B monoubiquitylation. Mol. Cell 46, 662-673. doi: 10.1016/j.molcel.2012. 05.023

Garaycoechea, J. I., Crossan, G. P., Langevin, F., Daly, M., Arends, M. J., and Patel, K. J. (2012). Genotoxic consequences of endogenous aldehydes on mouse haematopoietic stem cell function. Nature 489, 571-575. doi: $10.1038 /$ nature 11368

Gatti, M., Pinato, S., Maiolica, A., Rocchio, F., Prato, M. G., Aebersold, R., et al. (2015). RNF168 promotes noncanonical K27 ubiquitination to signal DNA damage. Cell Rep. 10, 226-238. doi: 10.1016/j.celrep.2014.12.021

Gatti, M., Pinato, S., Maspero, E., Soffientini, P., Polo, S., and Penengo, L. (2012). A novel ubiquitin mark at the $\mathrm{N}$-terminal tail of histone H2As targeted by 
RNF168 ubiquitin ligase. Cell cycle (Georgetown, Tex) 11, 2538-2544. doi: $10.4161 /$ cc.20919

Gatzka, M., Tasdogan, A., Hainzl, A., Allies, G., Maity, P., Wilms, C., et al. (2015). Interplay of H2A deubiquitinase 2A-DUB/Mysm1 and the p19/p53 axis in hematopoiesis, early T-cell development and tissue differentiation. Cell Death Differ. 22, 1451-1462. doi: 10.1038/cdd.2014.231

Geiger, H., De Haan, G., and Florian, M. C. (2013). The ageing haematopoietic stem cell compartment. Nat. Rev. Immunol. 13, 376-389. doi: 10.1038/nri3433

Gieni, R. S., Ismail, I. H., Campbell, S., and Hendzel, M. J. (2011). Polycomb group proteins in the DNA damage response-A link between radiation resistance and "stemness." Cell Cycle 10, 883-894. doi: 10.4161/cc.10.6.14907

Ginjala, V., Nacerddine, K., Kulkarni, A., Oza, J., Hill, S., Yao, M., et al. (2011). BMI1 is recruited to DNA breaks and contributes to DNA damageinduced H2A ubiquitination and repair. Mol. Cell. Biol. 31, 1972-1982. doi: 10.1128/MCB.00981-10

Goldknopf, I., and Busch, H. (1977). Isopeptide linkage between nonhistone and histone 2A polypeptides of chromosomal conjugate-protein A24. Proc. Natl. Acad. Sci. U.S.A. 74, 864-868. doi: 10.1073/pnas.74.3.864

Goldstein, M., and Kastan, M. B. (2015). Repair versus checkpoint functions of Brcal are differentially regulated by site of chromatin binding. Cancer Res. 75, 2699-2707. doi: 10.1158/0008-5472.CAN-15-0400

Gong, F., Chiu, L. Y., Cox, B., Aymard, F., Clouaire, T., Leung, J. W., et al. (2015). Screen identifies bromodomain protein ZMYND8 in chromatin recognition of transcription-associated DNA damage that promotes homologous recombination. Genes Dev. 29, 197-211. doi: 10.1101/gad.252189.114

Greenberg, R. A., Sobhian, B., Pathania, S., Cantor, S. B., Nakatani, Y., and Livingston, D. M. (2006). Multifactorial contributions to an acute DNA damage response by BRCA1/BARD1-containing complexes. Genes Dev. 20, 34-46. doi: $10.1101 / \mathrm{gad} .1381306$

Gudjonsson, T., Altmeyer, M., Savic, V., Toledo, L., Dinant, C., Grøfte, M., et al. (2012). TRIP12 and UBR5 suppress spreading of chromatin ubiquitylation at damaged chromosomes. Cell 150, 697-709. doi: 10.1016/j.cell.2012.06.039

Harbour, J. W., Onken, M. D., Roberson, E. D., Duan, S., Cao, L., Worley, L. A., et al. (2010). Frequent mutation of BAP1 in metastasizing uveal melanomas. Science 330, 1410-1413. doi: 10.1126/science.1194472

Henry, K. W., Wyce, A., Lo, W. S., Duggan, L. J., Emre, N. C., Kao, C. F., et al. (2003). Transcriptional activation via sequential histone H2B ubiquitylation and deubiquitylation, mediated by SAGA-associated Ubp8. Genes Dev. 17, 2648-2663. doi: 10.1101/gad.1144003

Herhaus, L., Al-Salihi, M., Macartney, T., Weidlich, S., and Sapkota, G. P. (2013). OTUB1 enhances TGFbeta signalling by inhibiting the ubiquitylation and degradation of active SMAD2/3. Nat. Commun. 4, 2519. doi: 10.1038/ncomms3519

Heride, C., Urbe, S., and Clague, M. J. (2014). Ubiquitin code assembly and disassembly. Curr. Biol. 24, R215-R220. doi: 10.1016/j.cub.2014. 02.002

Hu, Y., Scully, R., Sobhian, B., Xie, A., Shestakova, E., and Livingston, D. (2011). RAP80-directed tuning of BRCA1 homologous recombination function at ionizing radiation-induced nuclear foci. Genes Dev. 25, 685-700. doi: 10.1101/gad.2011011

Huen, M., Grant, R., Manke, I., Minn, K., Yu, X., Yaffe, M., et al. (2007). RNF8 Transduces the DNA-damage signal via histone ubiquitylation and checkpoint protein assembly. Cell 131, 901-914. doi: 10.1016/j.cell.2007.09.041

Ismail, I. H., Andrin, C., Mcdonald, D., and Hendzel, M. J. (2010). BMI1-mediated histone ubiquitylation promotes DNA double-strand break repair. J. Cell Biol. 191, 45-60. doi: 10.1083/jcb.201003034

Ismail, I. H., Davidson, R., Gagne, J. P., Xu, Z. Z., Poirier, G. G., and Hendzel, M. J. (2014). Germline mutations in BAP1 impair its function in DNA double-strand break repair. Cancer Res. 74, 4282-4294. doi: 10.1158/0008-5472.CAN-13-3109

Ito, K., Hirao, A., Arai, F., Matsuoka, S., Takubo, K., Hamaguchi, I., et al. (2004). Regulation of oxidative stress by ATM is required for self-renewal of haematopoietic stem cells. Nature 431, 997-1002. doi: 10.1038/nature02989

Jackson, S. P., and Bartek, J. (2009). The DNA-damage response in human biology and disease. Nature 461, 1071-1078. doi: 10.1038/nature08467

Jackson, S. P., and Durocher, D. (2013). Regulation of DNA damage responses by ubiquitin and SUMO. Mol. Cell 49, 795-807. doi: 10.1016/j.molcel.2013.01.017

Jacq, X., Kemp, M., Martin, N. M., and Jackson, S. P. (2013). Deubiquitylating enzymes and DNA damage response pathways. Cell Biochem. Biophys. 67, 25-43. doi: 10.1007/s12013-013-9635-3
Jensen, D. E., Proctor, M., Marquis, S. T., Gardner, H. P., Ha, S. I., Chodosh, L. A., et al. (1998). BAP1: a novel ubiquitin hydrolase which binds to the BRCA1 RING finger and enhances BRCA1-mediated cell growth suppression. Oncogene 16, 1097-1112. doi: 10.1038/sj.onc.1201861

Jiang, X.-X., Nguyen, Q., Chou, Y., Wang, T., Nandakumar, V., Yates, P., et al. (2011). Control of B cell development by the histone H2A deubiquitinase MYSM1. Immunity 35, 883-896. doi: 10.1016/j.immuni.2011.11.010

Joo, H., Zhai, L., Yang, C., Nie, S., Erdjument-Bromage, H., Tempst, P., et al. (2007). Regulation of cell cycle progression and gene expression by H2A deubiquitination. Nature 449, 1068-1072. doi: 10.1038/nature06256

Juang, Y. C., Landry, M. C., Sanches, M., Vittal, V., Leung, C. C., Ceccarelli, D. F., et al. (2012). OTUB1 co-opts Lys48-linked ubiquitin recognition to suppress E2 enzyme function. Mol. Cell 45, 384-397. doi: 10.1016/j.molcel.2012. 01.011

Kakarougkas, A., Ismail, A., Chambers, A. L., Riballo, E., Herbert, A. D., Kunzel, J., et al. (2014). Requirement for PBAF in transcriptional repression and repair at DNA breaks in actively transcribed regions of chromatin. Mol. Cell 55, 723-732. doi: 10.1016/j.molcel.2014.06.028

Kakarougkas, A., Ismail, A., Katsuki, Y., Freire, R., Shibata, A., and Jeggo, P. A. (2013). Co-operation of BRCA1 and POH1 relieves the barriers posed by 53BP1 and RAP80 to resection. Nucleic Acids Res. 41, 10298-10311. doi: $10.1093 /$ nar/gkt802

Kalb, R., Mallery, D. L., Larkin, C., Huang, J. T., and Hiom, K. (2014). BRCA1 is a histone-H2A-specific ubiquitin ligase. Cell Rep. 8, 999-1005. doi: 10.1016/j.celrep.2014.07.025

Kato, K., Nakajima, K., Ui, A., Muto-Terao, Y., Ogiwara, H., and Nakada, S. (2014). Fine-tuning of DNA damage-dependent ubiquitination by OTUB2 supports the DNA repair pathway choice. Mol. Cell 53, 617-630. doi: 10.1016/j.molcel.2014.01.030

Kim, J. M., Parmar, K., Huang, M., Weinstock, D. M., Ruit, C. A., Kutok, J. L., et al. (2010). Inactivation of murine Usp1 results in genomic instability and a Fanconi anemia phenotype. Dev. Cell 16, 314-320. doi: 10.1016/j.devcel.2009. 01.001

Knobel, P. A., Belotserkovskaya, R., Galanty, Y., Schmidt, C. K., Jackson, S. P., and Stracker, T. H. (2014). USP28 is recruited to sites of DNA damage by the tandem BRCT domains of 53BP1 but plays a minor role in double-strand break metabolism. Mol. Cell. Biol. 34, 2062-2074. doi: 10.1128/MCB.00197-14

Kolas, N., Chapman, J., Nakada, S., Ylanko, J., Chahwan, R., Sweeney, F., et al. (2007). Orchestration of the DNA-damage response by the RNF8 ubiquitin ligase. Science 318, 1637-1640. doi: 10.1126/science.1150034

Komander, D., Clague, M. J., and Urbé, S. (2009). Breaking the chains: structure and function of the deubiquitinases. Nat. Rev. Mol. Cell Biol. 10, 550-563. doi: $10.1038 / \mathrm{nrm} 2731$

Komander, D., and Rape, M. (2012). The ubiquitin code. Annu. Rev. Biochem. 81, 203-229. doi: 10.1146/annurev-biochem-060310-170328

Kulathu, Y., and Komander, D. (2012). Atypical ubiquitylation - the unexplored world of polyubiquitin beyond Lys48 and Lys63 linkages. Nat. Rev. Mol. Cell Biol. 13, 508-523. doi: 10.1038/nrm3394

Lancini, C., Van Den Berk, P. C., Vissers, J. H., Gargiulo, G., Song, J. Y., Hulsman, D., et al. (2014). Tight regulation of ubiquitin-mediated DNA damage response by USP3 preserves the functional integrity of hematopoietic stem cells. J. Exp. Med. 211, 1759-1777. doi: 10.1084/jem.20131436

Lessard, J., and Sauvageau, G. (2003). Bmi-1 determines the proliferative capacity of normal and leukaemic stem cells. Nature 423, 255-260. doi: 10.1038 /nature 01572

Leung, J. W., Agarwal, P., Canny, M. D., Gong, F., Robison, A. D., Finkelstein, I. J., et al. (2014). Nucleosome acidic patch promotes RNF168- and RING1B/BMI1dependent $\mathrm{H} 2 \mathrm{AX}$ and $\mathrm{H} 2 \mathrm{~A}$ ubiquitination and DNA damage signaling. PLoS Genet. 10:e1004178. doi: 10.1371/journal.pgen.1004178

Li, L., Halaby, M., Hakem, A., Cardoso, R., El Ghamrasni, S., Harding, S., et al. (2010). Rnf8 deficiency impairs class switch recombination, spermatogenesis, and genomic integrity and predisposes for cancer. J. Exp. Med. 207, 983-997. doi: 10.1084/jem.20092437

Liakath-Ali, K., Vancollie, V. E., Heath, E., Smedley, D. P., Estabel, J., Sunter, D., et al. (2014). Novel skin phenotypes revealed by a genome-wide mouse reverse genetic screen. Nat. Commun. 5, 3540. doi: 10.1038/ncomms4540

Liu, C., Wu, J., Paudyal, S. C., You, Z., and Yu, X. (2013). CHFR is important for the first wave of ubiquitination at DNA damage sites. Nucleic Acids Res. 41, 1698-1710. doi: 10.1093/nar/gks1278 
Liu, J., Cao, L., Chen, J., Song, S., Lee, I. H., Quijano, C., et al. (2009). Bmil regulates mitochondrial function and the DNA damage response pathway. Nature 459, 387-392. doi: 10.1038/nature08040

Lorenzo, L. P., Chen, H., Shatynski, K. E., Clark, S., Yuan, R., Harrison, D. E., et al. (2011). Defective hematopoietic stem cell and lymphoid progenitor development in the Ts65Dn mouse model of Down syndrome: potential role of oxidative stress. Antioxid. Redox Signal. 15, 2083-2094. doi: $10.1089 /$ ars. 2010.3798

Lui, T. T., Lacroix, C., Ahmed, S. M., Goldenberg, S. J., Leach, C. A., Daulat, A. M., et al. (2011). The ubiquitin-specific protease USP34 regulates axin stability and Wnt/beta-catenin signaling. Mol. Cell. Biol. 31, 2053-2065. doi: 10.1128/MCB.01094-10

Lukas, J., Lukas, C., and Bartek, J. (2011). More than just a focus: the chromatin response to DNA damage and its role in genome integrity maintenance. Nat. Cell Biol. 13, 1161-1169. doi: 10.1038/ncb2344

Mailand, N., Bekker-Jensen, S., Faustrup, H., Melander, F., Bartek, J., Lukas, C., et al. (2007). RNF8 ubiquitylates histones at DNA double-strand breaks and promotes assembly of repair proteins. Cell 131, 887-900. doi: 10.1016/j.cell.2007.09.040

Mallette, F. A., Mattiroli, F., Cui, G., Young, L. C., Hendzel, M. J., Mer, G., et al. (2012). RNF8- and RNF168-dependent degradation of KDM4A/JMJD2A triggers 53BP1 recruitment to DNA damage sites. EMBO J. 31, 1865-1878. doi: 10.1038/emboj.2012.47

Matsuoka, S., Ballif, B. A., Smogorzewska, A., Mcdonald, E. R. III, Hurov, K. E., Luo, J., et al. (2007). ATM and ATR substrate analysis reveals extensive protein networks responsive to DNA damage. Science 316, 1160-1166. doi: $10.1126 /$ science. 1140321

Mattiroli, F., Vissers, J. H. A., Van Dijk, W. J., Ikpa, P., Citterio, E., Vermeulen, W., et al. (2012). RNF168 ubiquitinates K13-15 on H2A/H2AX to drive DNA damage signaling. Cell 150, 1182-1195. doi: 10.1016/j.cell.2012. 08.005

Meerang, M., Ritz, D., Paliwal, S., Garajova, Z., Bosshard, M., Mailand, N., et al. (2011). The ubiquitin-selective segregase $\mathrm{VCP} / \mathrm{p} 97$ orchestrates the response to DNA double-strand breaks. Nat. Cell Biol. 13, 1376-1382. doi: 10.1038/ ncb2367

Mevissen, T. E., Hospenthal, M. K., Geurink, P. P., Elliott, P. R., Akutsu, M., Arnaudo, N., et al. (2013). OTU deubiquitinases reveal mechanisms of linkage specificity and enable ubiquitin chain restriction analysis. Cell 154, 169-184. doi: $10.1016 /$ j.cell.2013.05.046

Morris, J. R., and Solomon, E. (2004). BRCA1: BARD1 induces the formation of conjugated ubiquitin structures, dependent on K6 of ubiquitin, in cells during DNA replication and repair. Hum. Mol. Genet. 13, 807-817. doi: $10.1093 / \mathrm{hmg} / \mathrm{ddh} 095$

Mosbech, A., Lukas, C., Bekker-Jensen, S., and Mailand, N. (2013). The deubiquitylating enzyme USP44 counteracts the DNA double-strand break response mediated by the RNF8 and RNF168 ubiquitin ligases. J. Biol. Chem. 288, 16579-16587. doi: 10.1074/jbc.M113.459917

Moyal, L., Lerenthal, Y., Gana-Weisz, M., Mass, G., So, S., Wang, S.-Y., et al. (2011). Requirement of ATM-dependent monoubiquitylation of histone H2B for timely repair of DNA double-strand breaks. Mol. Cell 41, 529-542. doi: 10.1016/j.molcel.2011.02.015

Nakada, S., Tai, I., Panier, S., Al-Hakim, A., Iemura, S.-I., Juang, Y.-C., et al. (2010). Non-canonical inhibition of DNA damage-dependent ubiquitination by OTUB1. Nature 466, 941-946. doi: 10.1038/nature09297

Nakamura, K., Kato, A., Kobayashi, J., Yanagihara, H., Sakamoto, S., Oliveira, D. V. N. P., et al. (2011). Regulation of homologous recombination by RNF20-dependent H2B ubiquitination. Mol. Cell 41, 515-528. doi: 10.1016/j.molcel.2011.02.002

Nandakumar, V., Chou, Y., Zang, L., Huang, X. F., and Chen, S. Y. (2013). Epigenetic control of natural killer cell maturation by histone H2A deubiquitinase, MYSM1. Proc. Natl. Acad. Sci. U.S.A. 110, E3927-E3936. doi: $10.1073 /$ pnas. 1308888110

Nicassio, F., Corrado, N., Vissers, J. H., Areces, L. B., Bergink, S., Marteijn, J. A., et al. (2007). Human USP3 is a chromatin modifier required for S phase progression and genome stability. Curr. Biol. 17, 1972-1977. doi: 10.1016/j.cub.2007.10.034

Niedernhofer, L. J. (2008). DNA repair is crucial for maintaining hematopoietic stem cell function. DNA Repair (Amst) 7, 523-529. doi: 10.1016/j.dnarep.2007.11.012
Nijman, S., Luna-Vargas, M., Velds, A., Brummelkamp, T., Dirac, A., Sixma, T., et al. (2005). A genomic and functional inventory of deubiquitinating enzymes. Cell 123, 773-786. doi: 10.1016/j.cell.2005.11.007

Nijnik, A., Clare, S., Hale, C., Raisen, C., Mcintyre, R. E., Yusa, K., et al. (2012). The critical role of histone H2A-deubiquitinase Mysm1 in hematopoiesis and lymphocyte differentiation. Blood 119, 1370-1379. doi: 10.1182/blood-2011-05352666

Nijnik, A., Woodbine, L., Marchetti, C., Dawson, S., Lambe, T., Liu, C., et al. (2007). DNA repair is limiting for haematopoietic stem cells during ageing. Nature 447, 686-690. doi: 10.1038/nature05875

Nishi, R., Wijnhoven, P., Le Sage, C., Tjeertes, J., Galanty, Y., Forment, J. V., et al. (2014). Systematic characterization of deubiquitylating enzymes for roles in maintaining genome integrity. Nat. Cell Biol. 16, 1011-1018. doi: $10.1038 /$ ncb3028

Nishikawa, H., Wu, W., Koike, A., Kojima, R., Gomi, H., Fukuda, M., et al. (2009). BRCA1-associated protein 1 interferes with BRCA1/BARD1 RING heterodimer activity. Cancer Res. 69, 111-119. doi: 10.1158/0008-5472.CAN-08-3355

Okamoto, K., Bartocci, C., Ouzounov, I., Diedrich, J. K., Yates Iii, J. R., and Denchi, E. L. (2013). A two-step mechanism for TRF2-mediated chromosome-end protection. Nature 494, 502-505. doi: 10.1038/nature 11873

Orthwein, A., Fradet-Turcotte, A., Noordermeer, S. M., Canny, M. D., Brun, C. M., Strecker, J., et al. (2014). Mitosis inhibits DNA double-strand break repair to guard against telomere fusions. Science 344, 189-193. doi: $10.1126 /$ science. 1248024

Pan, M.-R., Peng, G., Hung, W.-C., and Lin, S.-Y. (2011). Monoubiquitination of H2AX regulates DNA damage response signaling. J. Biol. Chem. 286, 2859928607. doi: 10.1074/jbc.M111.256297

Panier, S., and Boulton, S. J. (2014). Double-strand break repair: 53BP1 comes into focus. Nat. Rev. Mol. Cell Biol. 15, 7-18. doi: 10.1038/nrm3719

Panier, S., and Durocher, D. (2013). Push back to respond better: regulatory inhibition of the DNA double-strand break response. Nat. Rev. Mol. Cell Biol. 14, 661-672. doi: 10.1038/nrm3659

Panier, S., Ichijima, Y., Fradet-Turcotte, A., Leung, C. C., Kaustov, L., Arrowsmith, C. H., et al. (2012). Tandem protein interaction modules organize the ubiquitindependent response to DNA double-strand breaks. Mol. Cell 47, 383-395. doi: 10.1016/j.molcel.2012.05.045

Park, I. K., Qian, D., Kiel, M., Becker, M. W., Pihalja, M., Weissman, I. L., et al. (2003). Bmi-1 is required for maintenance of adult self-renewing haematopoietic stem cells. Nature 423, 302-305. doi: 10.1038/nature01587

Parmar, K., Kim, J., Sykes, S., Shimamura, A., Stuckert, P., Zhu, K., et al. (2010). Hematopoietic stem cell defects in mice with deficiency of Fancd2 or Usp1. Stem Cells 28, 1186-1195. doi: 10.1002/stem.437

Peña-Llopis, S., Vega-Rubín-De-Celis, S., Liao, A., Leng, N., Pavía-Jiménez, A., Wang, S., et al. (2012). BAP1 loss defines a new class of renal cell carcinoma. Nat. Genet. 44, 751-759. doi: 10.1038/ng.2323

Pereg, Y., Liu, B. Y., O'rourke, K. M., Sagolla, M., Dey, A., Komuves, L., et al. (2010). Ubiquitin hydrolase Dub3 promotes oncogenic transformation by stabilizing Cdc25A. Nat. Cell Biol. 12, 400-406. doi: 10.1038/ncb2041

Peuscher, M. H., and Jacobs, J. J. (2011). DNA-damage response and repair activities at uncapped telomeres depend on RNF8. Nat. Cell Biol. 13, 1139-1145. doi: $10.1038 /$ ncb2326

Pinato, S., Scandiuzzi, C., Arnaudo, N., Citterio, E., Gaudino, G., and Penengo, L. (2009). RNF168, a new RING finger, MIU-containing protein that modifies chromatin by ubiquitination of histones H2A and H2AX. BMC Mol. Biol. 10:55. doi: 10.1186/1471-2199-10-55

Poulsen, M., Lukas, C., Lukas, J., Bekker-Jensen, S., and Mailand, N. (2012). Human RNF169 is a negative regulator of the ubiquitin-dependent response to DNA double-strand breaks. J. Cell Biol. 197, 189-199. doi: 10.1083/jcb.2011 09100

Rossi, D. J., Bryder, D., Seita, J., Nussenzweig, A., Hoeijmakers, J., and Weissman, I. L. (2007). Deficiencies in DNA damage repair limit the function of haematopoietic stem cells with age. Nature 447, 725-729. doi: $10.1038 /$ nature 05862

Rübe, C., Fricke, A., Widmann, T., Fürst, T., Madry, H., Pfreundschuh, M., et al. (2011). Accumulation of DNA damage in hematopoietic stem and progenitor cells during human aging. PLoS ONE 6:e17487. doi: 10.1371/journal.pone.0017487

Sahtoe, D. D., and Sixma, T. K. (2015). Layers of DUB regulation. Trends Biochem. Sci. 40, 456-467. doi: 10.1016/j.tibs.2015.05.002 
Santos, M., Huen, M., Jankovic, M., Chen, H., Lopez-Contreras, A., Klein, I., et al. (2010). Class switching and meiotic defects in mice lacking the E3 ubiquitin ligase RNF8. J. Exp. Med. 207, 973-981. doi: 10.1084/jem.20092308

Scheuermann, J. C., de Ayala Alonso, A. G., Oktaba, K., Ly-Hartig, N., Mcginty, R. K., Fraterman, S., et al. (2010). Histone H2A deubiquitinase activity of the Polycomb repressive complex PR-DUB. Nature 465, 243-247. doi: 10.1038 /nature 08966

Shanbhag, N. M., Rafalska-Metcalf, I. U., Balane-Bolivar, C., Janicki, S. M., and Greenberg, R. A. (2010). ATM-dependent chromatin changes silence transcription in cis to DNA double-strand breaks. Cell 141, 970-981. doi: 10.1016/j.cell.2010.04.038

Shao, G., Lilli, D. R., Patterson-Fortin, J., Coleman, K. A., Morrissey, D. E., and Greenberg, R. A. (2009). The Rap80-BRCC36 de-ubiquitinating enzyme complex antagonizes RNF8-Ubc13-dependent ubiquitination events at DNA double strand breaks. Proc. Natl. Acad. Sci. U.S.A. 106, 3166-3171. doi: 10.1073/pnas.0807485106

Sharma, N., Zhu, Q., Wani, G., He, J., Wang, Q. E., and Wani, A. A. (2014). USP3 counteracts RNF168 via deubiquitinating $\mathrm{H} 2 \mathrm{~A}$ and gammaH2AX at lysine 13 and 15. Cell Cycle 13, 106-114. doi: 10.4161/cc.26814

Shiloh, Y., Shema, E., Moyal, L., and Oren, M. (2011). RNF20-RNF40: a ubiquitindriven link between gene expression and the DNA damage response. FEBS Lett. 585, 2795-2802. doi: 10.1016/j.febslet.2011.07.034

Sloper-Mould, K. E., Eyre, H. J., Wang, X.-W., Sutherland, G. R., and Baker, R. T. (1999). Characterization and chromosomal localization of USP3, a novel human ubiquitin-specific protease. J. Biol. Chem. 274, 26878-26884. doi: 10.1074/jbc.274.38.26878

Smeenk, G., Wiegant, W. W., Marteijn, J. A., Luijsterburg, M. S., Sroczynski, N., Costelloe, T., et al. (2013). Poly(ADP-ribosyl)ation links the chromatin remodeler SMARCA5/SNF2H to RNF168-dependent DNA damage signaling. J. Cell Sci. 126, 889-903. doi: 10.1242/jcs.109413

Sobhian, B., Shao, G., Lilli, D. R., Culhane, A. C., Moreau, L. A., Xia, B., et al. (2007). RAP80 targets BRCA1 to specific ubiquitin structures at DNA damage sites. Science 316, 1198-1202. doi: 10.1126/science.1139516

Song, E. J., Werner, S. L., Neubauer, J., Stegmeier, F., Aspden, J., Rio, D., et al. (2010). The Prp19 complex and the Usp4Sart3 deubiquitinating enzyme control reversible ubiquitination at the spliceosome. Genes Dev. 24, 1434-1447. doi: $10.1101 /$ gad.1925010

Sowa, M. E., Bennett, E. J., Gygi, S. P., and Harper, J. (2009). Defining the human deubiquitinating enzyme interaction landscape. Cell 138, 389-403. doi: 10.1016/j.cell.2009.04.042

Sparmann, A., and van Lohuizen, M. (2006). Polycomb silencers control cell fate, development and cancer. Nat. Rev. Cancer 6, 846-856. doi: 10.1038/ nrc1991

Stegmeier, F., Rape, M., Draviam, V., Nalepa, G., Sowa, M., Ang, X., et al. (2007). Anaphase initiation is regulated by antagonistic ubiquitination and deubiquitination activities. Nature 446, 876-881. doi: 10.1038/nature05694

Stewart, G. S., Panier, S., Townsend, K., Al-Hakim, A. K., Kolas, N. K., Miller, E. S., et al. (2009). The RIDDLE syndrome protein mediates a ubiquitindependent signaling cascade at sites of DNA damage. Cell 136, 420-434. doi: 10.1016/j.cell.2008.12.042

Sun, X. X., Challagundla, K. B., and Dai, M. S. (2012). Positive regulation of p53 stability and activity by the deubiquitinating enzyme Otubain 1. EMBO J. 31, 576-592. doi: 10.1038/emboj.2011.434

Sy, S. M., Jiang, J., O, W. S., Deng, Y., and Huen, M. S. (2013). The ubiquitin specific protease USP34 promotes ubiquitin signaling at DNA double-strand breaks. Nucleic Acids Res. 41, 8572-8580. doi: 10.1093/nar/gkt622

TCGA. (2012). Comprehensive genomic characterization of squamous cell lung cancers. Nature 489, 519-525. doi: 10.1038/nature11404

Tse, W. K., Eisenhaber, B., Ho, S. H., Ng, Q., Eisenhaber, F., and Jiang, Y.-J. (2009). Genome-wide loss-of-function analysis of deubiquitylating enzymes for zebrafish development. BMC Genomics 10:637. doi: 10.1186/1471-216410-637

Tsou, W. L., Sheedlo, M. J., Morrow, M. E., Blount, J. R., Mcgregor, K. M., Das, C., et al. (2012). Systematic analysis of the physiological importance of deubiquitinating enzymes. PLOS ONE 7:e43112. doi: 10.1371/journal.pone.0043112

Ui, A., Nagaura, Y., and Yasui, A. (2015). Transcriptional elongation factor ENL phosphorylated by ATM recruits polycomb and switches off transcription for DSB repair. Mol. Cell 58, 468-482. doi: 10.1016/j.molcel.2015.03.023
Ulrich, H. D. (2012). Ubiquitin and SUMO in DNA repair at a glance. J. Cell Sci. 125, 249-254. doi: 10.1242/jcs.091801

van der Laan, S., Tsanov, N., Crozet, C., and Maiorano, D. (2013). High Dub3 expression in mouse ESCs couples the G1/S checkpoint to pluripotency. Mol. Cell 52, 366-379. doi: 10.1016/j.molcel.2013.10.003

Vissers, J. H., Van Lohuizen, M., and Citterio, E. (2012). The emerging role of Polycomb repressors in the response to DNA damage. J. Cell Sci. 125, 3939-3948. doi: 10.1242/jcs. 107375

Walter, D., Lier, A., Geiselhart, A., Thalheimer, F. B., Huntscha, S., Sobotta, M. C., et al. (2015). Exit from dormancy provokes DNA-damage-induced attrition in haematopoietic stem cells. Nature 520, 549-552. doi: 10.1038/nature14131

Wang, B., and Elledge, S. (2007). Ubc13/Rnf8 ubiquitin ligases control foci formation of the Rap80/Abraxas/Brca1/Brcc36 complex in response to DNA damage. Proc. Natl. Acad. Sci. U.S.A. 104, 20759-20763. doi: 10.1073/pnas.0710061104

Wang, B., Matsuoka, S., Ballif, B. A., Zhang, D., Smogorzewska, A., Gygi, S. P., et al. (2007). Abraxas and RAP80 form a BRCA1 protein complex required for the DNA damage response. Science 316, 1194-1198. doi: 10.1126/science.1139476

Wang, H., Wang, L., Erdjument-Bromage, H., Vidal, M., Tempst, P., Jones, R., et al. (2004). Role of histone H2A ubiquitination in Polycomb silencing. Nature 431, 873-878. doi: 10.1038/nature02985

Wang, J., Sun, Q., Morita, Y., Jiang, H., Groß, A., Lechel, A., et al. (2012). A differentiation checkpoint limits hematopoietic stem cell self-renewal in response to DNA damage. Cell 148, 1001-1014. doi: 10.1016/j.cell.2012.01.040

Wang, T., Nandakumar, V., Jiang, X. X., Jones, L., Yang, A. G., Huang, X. F., et al. (2013). The control of hematopoietic stem cell maintenance, self-renewal, and differentiation by Mysm1-mediated epigenetic regulation. Blood 122, 28122822. doi: 10.1182/blood-2013-03-489641

Wiener, R., Zhang, X., Wang, T., and Wolberger, C. (2012). The mechanism of OTUB1-mediated inhibition of ubiquitination. Nature 483, 618-622. doi: 10.1038 /nature 10911

Wiltshire, T., Lovejoy, C., Wang, T., Xia, F., O'connor, M., and Cortez, D. (2010). Sensitivity to poly(ADP-ribose) polymerase (PARP) inhibition identifies ubiquitin-specific peptidase 11 (USP11) as a regulator of DNA doublestrand break repair. J. Biol. Chem. 285, 14565-14571. doi: 10.1074/jbc.M110. 104745

Won, H., Nandakumar, V., Yates, P., Sanchez, S., Jones, L., Huang, X. F., et al. (2014). Epigenetic control of dendritic cell development and fate determination of common myeloid progenitor by Mysm1. Blood 124, 2647-2656. doi: 10.1182/blood-2013-10-534313

Wu, C., Kang, H., Yang, W., Wu, J., Jeong, Y., Wang, J., et al. (2011a). The critical role of monoubiquitination of Histone H2AX in Histone H2AX phosphorylation and DNA damage response. J. Biol. Chem. 286, 30806-30815. doi: 10.1074/jbc.M111.257469

Wu, J., Chen, Y., Lu, L. Y., Wu, Y., Paulsen, M. T., Ljungman, M., et al. (2011b). Chfr and RNF8 synergistically regulate ATM activation. Nat. Struct. Mol. Biol. 18, 761-768. doi: 10.1038/nsmb.2078

Yang, W., Lee, Y. H., Jones, A. E., Woolnough, J. L., Zhou, D., Dai, Q., et al (2014). The histone H2A deubiquitinase Usp16 regulates embryonic stem cell gene expression and lineage commitment. Nat. Commun. 5, 3818. doi: $10.1038 /$ ncomms 4818

Yao, T., and Cohen, R. E. (2002). A cryptic protease couples deubiquitination and degradation by the proteasome. Nature 419, 403-407. doi: 10.1038/nature01071

Yin, Z., Menendez, D., Resnick, M. A., French, J. E., Janardhan, K. S., and Jetten, A. M. (2012). RAP80 is critical in maintaining genomic stability and suppressing tumor development. Cancer Res. 72, 5080-5090. doi: 10.1158/00085472.CAN-12-1484

Yoneyama, M., Tochio, N., Umehara, T., Koshiba, S., Inoue, M., Yabuki, T., et al. (2007). Structural and functional differences of SWIRM domain subtypes. J. Mol. Biol. 369, 222-238. doi: 10.1016/j.jmb.2007.03.027

Yu, H., Pak, H., Hammond-Martel, I., Ghram, M., Rodrigue, A., Daou, S., et al. (2014). Tumor suppressor and deubiquitinase BAP1 promotes DNA double-strand break repair. Proc. Natl. Acad. Sci. U.S.A. 111, 285-290. doi: 10.1073/pnas.1309085110

Zhang, W., and Sidhu, S. S. (2014). Development of inhibitors in the ubiquitination cascade. FEBS Lett. 588, 356-367. doi: 10.1016/j.febslet.2013.11.003

Zhang, Y., Foreman, O., Wigle, D. A., Kosari, F., Vasmatzis, G., Salisbury, J. L., et al. (2012). USP44 regulates centrosome positioning to prevent aneuploidy and suppress tumorigenesis. J. Clin. Invest. 122, 4362-4374. doi: 10.1172/JCI63084 
Zhang, Y., Van Deursen, J., and Galardy, P. J. (2011). Overexpression of ubiquitin specific protease 44 (USP44) induces chromosomal instability and is frequently observed in human T-cell leukemia. PLOS ONE 6:e23389. doi: 10.1371/journal.pone.0023389

Zhang, Z., Yang, H., and Wang, H. (2014). The histone H2A deubiquitinase USP16 interacts with HERC2 and fine-tunes cellular response to DNA damage. J. Biol. Chem. 289, 32883-32894. doi: 10.1074/jbc.M114.599605

Zheng, H., Gupta, V., Patterson-Fortin, J., Bhattacharya, S., Katlinski, K., Wu, J., et al. (2013). A BRISC-SHMT complex deubiquitinates IFNAR1 and regulates interferon responses. Cell Rep. 5, 180-193. doi: 10.1016/j.celrep.2013. 08.025

Zhu, P., Zhou, W., Wang, J., Puc, J., Ohgi, K., Erdjument-Bromage, H., et al. (2007). A histone $\mathrm{H} 2 \mathrm{~A}$ deubiquitinase complex coordinating histone acetylation and
H1 dissociation in transcriptional regulation. Mol. Cell 27, 609-621. doi: 10.1016/j.molcel.2007.07.024

Conflict of Interest Statement: The author declares that the research was conducted in the absence of any commercial or financial relationships that could be construed as a potential conflict of interest.

Copyright (C) 2015 Citterio. This is an open-access article distributed under the terms of the Creative Commons Attribution License (CC BY). The use, distribution or reproduction in other forums is permitted, provided the original author(s) or licensor are credited and that the original publication in this journal is cited, in accordance with accepted academic practice. No use, distribution or reproduction is permitted which does not comply with these terms. 